ISSN: 0213-2060

DOI: https://doi.org/10.14201/shhme2018362938

\title{
LAS ESCUELAS DE GRAMÁTICA EN LA CASTILLA BAJOMEDIEVAL (SIGLOS XIII-XV)*
}

\section{Grammar Schools in Late Medieval Castile $\left(13^{\text {th }}-15^{\text {th }}\right.$ Centuries)}

\author{
Susana GUIJARRO GONZÁLEZ \\ Depto. de Ciencias Históricas. Facultad de Filosofía y Letras. Universidad de Cantabria. Avda. de los Castros, 52. \\ E-39005 SANTANDER. C. e.: susana.guijarro@unican.es
}

Recibido: 2018-03-20

Revisado: 2018-04-11

Aceptado: 2018-10-29

RESUMEN: Este artículo tiene como objeto determinar cuáles fueron los principales rasgos que definieron las denominadas escuelas de gramática en la Corona de Castilla en el contexto de las escuelas bajomedievales europeas. El análisis de la limitada información existente y recopilada sobre fundación, financiación, provisión de maestros y programas de estas escuelas trata de establecer similitudes y diferencias. A pesar de la existencia de ambas, el presente estudio subraya la existencia de un sistema escolar complejo y multipolar que las ciudades de la Castilla bajomedieval comparten con la Corona de Aragón y otros reinos europeos del periodo. Algunos de los parámetros utilizados para reconstruir el programa de dichas escuelas revelan la influencia del currículum de los Studia humanitatis y su contribución a los valores cívicos de la cultura urbana bajomedieval.

Palabras clave: Escuelas de gramática; Corona de Castilla; Corona de Aragón; Siglos XIV y Xv.

ABSTRACT: This paper aims to determine the main features that defined the so-called grammar schools in the Crown of Castile in the context of the Late Medieval European

* Algunos de los datos utilizados para este estudio han sido recopilados en el contexto de la investigación realizada dentro de los proyectos de investigación de I+D HAR2013-41179P y HAR2016-79265, que lleva por título: Cultura, poder y redes sociales en la Castilla medieval: el clero de las diócesis de Burgos y Sigüenza en la Baja Edad Media. 
LAS ESCUELAS DE GRAMÁTICA EN LA CASTILLA BAJOMEDIEVAL (SIGLOS XIII-XV)

SUSANA GUIJARRO GONZÁLEZ

10

school system. The analysis of the limited extant information that has been collected about the foundation, funding, appointment of masters and school syllabuses seeks to establish similarities and differences. Although both exist, the current study stresses the existence of a complex and diverse school system that the Late Medieval Castilian cities shared with the Crown of Aragon and other medieval European kingdoms. Some of the parameters used to rebuild the syllabus at the said schools reveal the influence of the Studia humanitatis curriculum and its contribution to the shaping of civic values in the urban culture of the Late Middle Ages.

Keywords: Grammar schools; Crown of Castile; Crown of Aragon; $14^{\text {th }}$ and $15^{\text {th }}$ Centuries.

SUMARIO: 0 Introducción. 1 Escuelas y maestros en la Castilla bajomedieval. 1.1 La regencia de las escuelas de gramática. 1.2 Financiación de las escuelas y salarios de los maestros. 1.3 La provisión de la Cátedra de gramática en las ciudades castellanas. 2 El currículum de las escuelas de gramática y los Studia humanitatis. 3 Conclusión. 4 Referencias bibliográficas.

\section{INTRODUCCIÓN}

A distinto ritmo e intensidad que en otras áreas europeas con un dinamismo urbano temprano, el crecimiento de las ciudades y el desarrollo comercial se afianzó en las ciudades castellanas a partir del siglo XIII y continuó en los siglos bajomedievales. Al igual que ocurrió en el resto del Occidente medieval, el avance del mundo urbano incidió en el sistema escolar y en la evolución de las universidades. La conciencia de la necesidad de un dominio de la lectura y escritura fue alcanzando a un número cada vez mayor de individuos dentro de los parámetros de la alfabetización minoritaria que caracterizó el Medievo. Las cancillerías laicas y eclesiásticas vieron aumentar los documentos escritos. Por otra parte, los contratos comerciales y privados, así como los documentos judiciales, requerían de escribanos, notarios y otros oficiales que los redactasen y validasen; a su vez las personas implicadas en estos procesos debían, al menos, ser capaces de entender el documento que les era leído en voz alta. Los comerciantes y artesanos debían gestionar la administración de sus negocios. En otras palabras, era difícil para gran parte de los habitantes de las ciudades escapar a un cierto nivel de familiaridad con el dominio creciente de la cultura escrita en la organización sociopolítica y económica de los centros urbanos. Por ello, la demanda escolar favoreció que, junto a las escuelas tradicionales (monásticas y catedralicias), proliferasen pequeñas escuelas, surgidas por iniciativa de un maestro laico o eclesiástico, y las denominadas escuelas de gramática, tras las cuales se advierte la participación del poder real y del poder municipal en su financiación.

Es arriesgado utilizar el binomio escuelas eclesiásticas/escuelas laicas en relación con las escuelas de gramática bajomedievales, pues los límites de separación entre ambas son cuando menos difusos. Esta dificultad conceptual a la hora de categorizar las escuelas bajomedievales no es privativa de las escuelas de la Corona de Castilla o, en menor medida, de las de la Corona de Aragón sino de la existencia en la Europa de estos siglos de 
un sistema escolar multipolar carente de una legislación uniforme. Otro escollo conceptual es la aplicación del término «laica» a una escuela que desde el siglo XIII en adelante parece traducirse más en su gratuidad y la apertura de la misma a clérigos y laicos que en su titularidad, gestión, financiación o currículum académico dirigidos por autoridades laicas. A grandes rasgos, las escuelas de gramática dependientes de las catedrales y obispos en ciudades episcopales y villas importantes de cada diócesis parecen haber sido dominantes en el sistema escolar castellano. Pero cualquier análisis sobre el mismo se topa con la inexistencia en los archivos de actas de protocolos notariales hasta comienzos del siglo XVI, lo cual hace imposible determinar si hubo contratos privados de maestros con familias, bien como preceptores o bien para abrir una escuela destinada a un grupo de escolares que deberían satisfacerle con el pago de una cuota. Algo bien diferente a lo que sucede con el estudio del sistema escolar en la Corona de Aragón, donde los archivos cuentan con fondos de protocolos notariales seriados desde la Baja Edad Media y donde ha sido posible documentar escuelas municipales y privadas junto a las escuelas de gramática o Artes dependientes del obispo y cabildo catedralicio.

Dada la estrecha conexión entre la escuela y el clero, el modelo escolar castellano se acercaría más al modelo de la Inglaterra bajomedieval donde Nicholas Orme percibe una cierta erosión del dominio clerical sobre la enseñanza entre 1380 y 1450 , momento en el que aumentó la fundación de escuelas de gramática gratuitas y abiertas a todos, cuyo gobierno en algunos casos era entregado a laicos, aunque seguiría habiendo más maestros clérigos que laicos ${ }^{1}$. Sin embargo, es una realidad puesta de manifiesto por estudios individualizados que en las áreas más urbanizadas de la Europa de los siglos XIII al XV obispos, cabildos catedralicios y gobiernos municipales participaron, ya fuera en convivencia pacífica o conflictiva, en alguna de las dimensiones que hicieron posibles las escuelas de gramática: fundación, nombramiento de maestros y financiación. Incluso en las florecientes ciudades del norte de Italia las escuelas comunales financiadas por los gobiernos municipales ofrecieron una enseñanza elemental y media solo a una fracción de la población urbana y entre los maestros de estas hubo clérigos. Con todo, puede afirmarse que fue en estas ciudades donde se dio el modelo más acabado del período de una escuela laica con diferentes tipologías, en el sentido de abiertas, aunque no gratuitas para los alumnos en todos los casos. Sin olvidar que hubo obispos y dignidades que actuaron como benefactores de escuelas elementales. En las ciudades pequeñas el contrato de maestros por los gobiernos comunales fue mayor, pero en las grandes ciudades mercantiles (Florencia, Venecia y Milán) se contrataban privadamente. También hubo escuelas de ábaco, documentadas desde el siglo XIII, sostenidas por los gobiernos municipales donde se formaba a los futuros artesanos y mercaderes en aritmética, geometría y administración de libros de contabilidad. Pocos entre los maestros de las escuelas comunales, los que servían como tutores en casa de una familia, los que enseñaban en su propia casa o los que dirigían escuelas con internado, habían obtenido un grado académico en las universidades. Algo que concuerda con el hecho de que en las facultades de Artes de las universidades fueron una minoría los que llegaron a graduarse. Haber pasado por las aulas era suficiente para

1 Orme, Nicholas. Education and Society in Medieval and Renaissance England. London-Ronceverte: Hambledon Press, 1989, pp. 4 y 26-28. 
ejercer como maestro en el lugar de origen del estudiante en Artes. Afamados humanistas como Guarino de Verona $(\dagger 1460)$ y Vittorino de Feltre $(† 1446)$ fundaron escuelas con internado. Al igual que las escuelas comunales, las escuelas independientes estaban guiadas por el objetivo pedagógico de introducir a los futuros oficiales de los gobiernos ciudadanos en los valores cívicos que definían el humanismo y en la búsqueda del bien común ${ }^{2}$.

En los territorios de Francia y el Sacro Imperio germánico aparecieron en los siglos XIV y XV escuelas patrocinadas por los gobiernos municipales. Sin embargo, esto no las situaba totalmente fuera del control eclesiástico. El obispo y el canciller/maestrescuela del cabildo catedralicio mantuvieron la competencia de conceder a los maestros la licentia docendi o permiso para enseñar dentro del espacio de jurisdicción diocesana. Estas escuelas lograron imponer gradualmente el uso de la lengua vernácula en la enseńanza y desde mediados del siglo xv fueron permeables a la recepción del humanismo ${ }^{3}$.

En la Corona de Aragón el paisaje escolar se aproxima a lo descrito para otras áreas del Occidente europeo. La conservación de actas de protocolos notariales permite documentar escuelas municipales y privadas junto a las propiamente eclesiásticas. Casos como el de Barbastro, en Huesca, donde las escuelas supervisadas por el obispo recibían sustento municipal, debieron ser comunes. En las villas las fuentes revelan la existencia de escuelas de gramática o Artes que reciben ambos nombres indistintamente (Teruel, Uncastillo, Tarazona, Daroca, Calatayud y Jaca). En Calatayud se mencionan entre 1320 y 1328 estudiantes de medicina y teología por lo que se trataría de un «Estudio de Artes» equiparable a la Facultad de Artes de las universidades que no había alcanzado el rango de Estudio General o universidad para lo cual, como es bien sabido, se requería la sanción pontificia. Y en Daroca se menciona en 1381 a un «maestro de Artes, lógica y natura", un testimonio ilustrativo de la posición que adquiere la Física o Filosofía natural de Aristóteles en el programa de los «Estudios de Artes» que ofrecían un nivel superior al de las escuelas de gramática elementales y medias. En Daroca, además, el rey Pedro IV de Aragón (1319-1387) instó a los oficiales del concejo a buscar un lugar para las escuelas cuando estas fueron destruidas. En Zaragoza fue también el poder real, Juan II, quien secundó la bula pontificia de Sixto IV por la que se concedía al «Estudio de Artes» de Zaragoza en 1474 capacidad para impartir el grado de bachiller en la persona del canciller (determinaba que este sería el arzobispo). Juan II (1398-1479) concedió en 1476 que el «Estudio de Artes» de Zaragoza pasase a ser un Estudio General aunque desde la perspectiva legal el año fundacional de la universidad zaragozana se pospuso $(1542)^{4}$.

En los territorios catalanes se conservan testimonios de la gestión municipal de escuelas en varias ciudades (Tarragona, Gerona, Reus, Montblanc, Cervera y Barcelona),

2 Grendler, Paul F. Schooling in Renaissance Italia. Literacy and Learning. 1300-1600. Baltimore-London: The John Hopkins University Press, 1989, pp. 11-22 y 23-35.

3 Russell, James E. German Higher Schools. The History, Organization and Methods of Secondary Education in Germany. London-Bombay-Calcuta: Longmans, 1910, pp. 2-15.

4 Falcón Pérez, María Isabel; Ledesma Rubio, M. ${ }^{a}$ Luisa; Orcástegui Gros, Carmen y Sarasa SÁNCHEZ, Esteban. «Las universidades del reino de Aragón (Huesca y Zaragoza) y de Lérida en la Edad Media». En Estudios sobre los orígenes de las universidades españolas. Homenaje de la Universidad de Valladolid a la de Bolonia en su IX centenario. Valladolid: Universidad de Valladolid, 1988, pp. 85-95. 
LAS ESCUELAS DE GRAMÁTICA EN LA CASTILLA BAJOMEDIEVAL (SIGLOS XIII-XV)

SUSANA GUIJARRO GONZÁLEZ

así como contratos a maestros privados y preceptores por las familias de la oligarquía urbana. El caso de Barcelona muestra el desencuentro de los poderes laicos y eclesiásticos que patrocinan la enseńanza escolar. La escuela de gramática estaba en los siglos XIV y XV bajo la tutela del obispo, pero el gobierno municipal o Consell participaba en su gobierno y pagaba los salarios de los maestros. En 1431 el rey Martín I (1356-1410) intentó promover un Estudio General para Barcelona, pero se topó con la resistencia de la burguesía mercantil representada en el Consell que recelaba de una institución que dependía del Papado y podía poner en peligro su autonomía. En cambio, el Consell no puso objeción en acordar con el cabildo catedralicio la creación de unas «escuelas mayores» por las mismas fechas. Ni tampoco en contratar maestros de derecho, filosofía o medicina ${ }^{5}$.

En los territorios valencianos la tradición del ejercicio de la enseńanza por maestros independientes, junto a las escuelas dependientes del cabildo catedralicio y las subvencionadas por el gobierno municipal, se remonta a la libertad de enseñanza que contemplaba el fuero (1261) concedido por Jaime I tras la conquista de Valencia (1238-1276). Para el segundo tercio del siglo XIV ya se documentan maestros laicos junto a maestros clérigos que han dejado atrás el precepto de gratuidad que habían difundido las escuelas altomedievales. Junto a estos maestros independientes la ciudad contaría con dos centros subvencionados, las escuelas mayores o escuelas de gramática dependientes de la catedral y las escuelas situadas en la puerta de Valldigna. En el siglo xv el intento de unificación del sistema escolar impulsado por el concejo se encontró no solamente con la resistencia eclesiástica sino con la ausencia por parte de la oligarquía urbana representada en el concejo de interés por articular una enseńanza municipal gratuita. Hay que decir que este desinterés de los gobiernos urbanos por forjar un dirigismo municipal de la enseñanza es perceptible en otras ciudades europeas. Al fin y al cabo, la enseñanza concejil subvencionada favorecía a los grupos dominantes que podían permitirse el pago de una cuota por sus hijos al maestro, a la par que se favorecía la iniciativa privada ${ }^{6}$.

\section{Escuelas y maestros en la Castilla bajomedieval}

Todo intento de análisis de la realidad de las denominadas escuelas de gramática bajomedievales se topa con una primera dificultad, la diversidad terminológica que ofrecen las fuentes para aludir a la misma: Escuelas de Gramática, Escuelas de Artes, Estudio de Gramática o Estudio de Artes, siendo la primera la más utilizada. Hasta bien entrado el siglo XIII es difícil encontrar estas expresiones. La enseñanza de la lectura, escritura y canto se desarrollaron dentro de las catedrales, generalmente en la zona claustral y en el coro. El cantor (chantre) iniciaba a los niños del coro en la notación musical y los primeros

5 Delgado Criado, Buenaventura. «La educación en Aragón: política educativa e instituciones docentes». En Historia de la educación en España y América. La educación en la España antigua y medieval. Madrid: Fundación Santamaría-Ediciones SM, 1992, vol. 1, pp. 318-345; Bartolomé MarTínez, Bernabé. "Instituciones docentes: Universidades y colegios universitarios». En Historia de la educación en España y América, vol. 1, pp. 554-602.

6 Cruselles Gómez, José María. Escuela y sociedad en la Valencia bajomedieval. Valencia: Diputación de Valencia, 1997, pp. 40-68. 
rudimentos de la lectura y escritura; y el magister scholarum (maestrescuela) les internaba en las disciplinas del Trivium (gramática, retórica y lógica), especialmente la gramática y, según los conocimientos del maestro, en algunas disciplinas del Quadrivium (aritmética, geometría, astronomía y música). La escuela catedralicia era la escuela por excelencia de las villas y ciudades episcopales, los alumnos eran clérigos ordenados al menos de órdenes menores y el maestro con sus conocimientos y ejemplo de vida era la encarnación de la escuela. Era el maestro quien hacía la escuela y su reputación la que atraía estudiantes de una geografía que superaba los propios límites de la diócesis. La mutación escolar que se gestó en el Occidente europeo, alumbrando las primeras universidades en los primeros decenios del siglo XIII, situó a las escuelas en una etapa de enseñanza base o intermedia, definitiva para la mayoría de los estudiantes y preparatoria para la minoría que accedía a las facultades superiores de las universidades (derecho, teología y medicina). Para entonces, la dignidad del magister scholarum, entre otras tareas, nombraba al maestro, pero no impartía docencia. Así lo muestran las constituciones otorgadas por legados pontificios a los cabildos castellanos durante el siglo XIII, haciéndose eco de las disposiciones escolares promulgadas por los concilios III (1179) y IV (1215) de Letrán. Si el primero exigía que todas las catedrales dispusieran de maestros que enseńasen a clérigos y a jóvenes pobres de forma gratuita, el segundo iba más allá, estableciendo que no solo las catedrales sino otras iglesias importantes de cada diócesis designaran un maestro que instruyese a los clérigos gratuitamente. Además, las sedes arzobispales deberían contar con un maestro de teología que enseñase las Sagradas Escrituras ${ }^{7}$.

El eco legislativo de las disposiciones lateranenses se dejó sentir en el Concilio provincial de Valladolid de 1228 que facilitó a los clérigos la asistencia a las escuelas para aprender gramática latina, reservándoles sus beneficios eclesiásticos durante la ausencia de los oficios y ceremonias litúrgicas diarias ${ }^{8}$. La asistencia de los clérigos a las escuelas no era privilegio del clero catedralicio, sino que había puesto en marcha un procedimiento de selección de candidatos entre los clérigos de las diócesis que estaba en marcha en el segundo decenio del siglo xiII. Al menos eso induce a pensar uno de los pocos sínodos que se celebraron en dicha centuria, el de Santiago de 1229

III Concilio de Letrán, año 1179, c. 18; Mansi, Jean D. (ed.). Sacrorum Conciliorum nova et amplissima collectio, reimpresión. Graz, 1960-1962, vol. 22, pp. 227-228: «ne pauperibus qui parentum opibus juvari non possunt legendi et proficiendi opportunitas subtrahantur, per unamquamque cathedralem ecclesiam magistro qui clericos eiusdem ecclesiae et scholares pauperes gratis doceat». IV Concilio de Letrán, año 1215, c. 11; Mansi, Sacrorum Conciliorum nova et amplissima collectio, vol. 22, p. 999: "ut non solum in qualibet cathedrali ecclesia sed etiam in aliis, quarum sufficere poterunt facultates, constituatur magister idoneus a praelato cum capitulo, seu majori ac saniori parte capituli, eligendus, qui clericos ecclesiarum ipsarum, et aliarum, gratis in grammaticae facultate ac aliis instruat juxta posse [...]. Sane metropolitana ecclesia theologum nichilominus habeat qui sacerdotes et alios in sacra pagina doceat $[. .$.$] ».$

8 Concilio provincial de Valladolid, año 1228; Tejada y Ramiro, Juan (ed.). Colección de cánones y de todos los concilios de la Iglesia de España y América. Madrid: Imprenta Pardo Montero, 1859-1863, vol. 3, p. 325: «De beneficiatis illiteratis: Stablecemos que todos los beneficiados que no saben fablar latin, sacados los vieios, que sean contreñidos, que aprendan, et que no les den beneficios fasta que sepan fablar latin. Otrosi, dispensamos con todos aquellos que quisieren estudiar, et aprovechar en gramatica, hayan los beneficios bien et entregamiente en las escolas, de la fiesta de San Luchas fasta tres ańos, se hi oviere otros clerigos por que la Iglesia sea servida». 
que determinaba que serían los arcedianos los encargados de hacer la selección de los más aptos para el estudio en sus arcedianatos ${ }^{9}$. No en vano el arzobispo Gelmírez $(† 1140)$ promovió el estudio de la oratoria y la lógica, y desde 1170 se documenta al maestrescuela compostelano designando un maestro para que enseńase gramática a los mozos del coro y a otros clérigos de la ciudad y diócesis ${ }^{10}$. En el mismo contexto han de situarse las constituciones otorgadas por los legados pontificios a los cabildos catedralicios castellanos que arrancaron con las concedidas por el Papa Honorio III en 1224 al cabildo de León. En estas se basaron las de Burgos, Palencia, Astorga y Toledo. Posteriormente, el legado Juan de Abbeville las reformaría entre 1228 y 1229, otorgándolas de nuevo a varios cabildos de las Coronas de Castilla y Aragón. Por entonces, en todas ellas el maestrescuela se hallaba instituido como dignidad y tenía competencias educativas en las catedrales, pero no impartía docencia ${ }^{11}$. El caso de Burgos constituye una excepción de la que se hablará posteriormente.

El alcance real de estas medidas es difícil de precisar, si bien las menciones a miembros de nueve de las catedrales de las actuales diócesis castellanoleonesas que aparecen intitulados con alguna de las variantes terminológicas de maestro antes de 1300 son significativas para dignidades y canónigos (magister, escolástico, maestro, etc.). Por sí solas no prueban que se trate de maestros que se hallasen ejerciendo la docencia, pero sí de personas con un cierto nivel de formación. Hay que esperar al siglo XIV para encontrar miembros de estos cabildos con el título de bachiller que en París se convirtió en un grado académico ya desde 1215. A algunos de ellos se les denomina bachilleres de la gramática, un título frecuente para aquellos que regentaban las escuelas de gramática ${ }^{12}$.

Frente a estas evidencias el Concilio de Valladolid de 1322, que serviría de referencia a los sínodos castellanos del siglo XIV y XV en materia de enseñanza y formación del clero, reiteraba que hubiese un maestro en gramática en dos o tres núcleos importantes de cada diócesis y que se facilitase a los que tuvieren un beneficio eclesiástico en alguna iglesia la asistencia a escuelas o universidades durante tres años. Este canon establecía lo que ya había previsto el Concilio IV lateranense (1215) más de una centuria antes, por lo que puede considerarse un reflejo de su limitado efecto en el reino de Castilla en cuanto al número de escuelas existentes. Sin embargo, deja entrever una realidad escolar más compleja en cuanto a los programas escolares, por ejemplo, diferencia a los maestros de lógica del resto, solo las villas importantes deberían disponer de tales maestros. El acceso de los seleccionados por el obispo y los cabildos catedralicios para estudiar en las facultades, tanto en la preparatoria Facultad de Artes como en las superiores de derecho y

9 Sínodo de Santiago, año 1229; García y García, Antonio (ed.). Synodicon Hispanum I. Galicia. Madrid: Biblioteca de Autores Cristianos, 1981, p. 264.

10 López Alsina, Fernando. «Marzoa, Melgar, Muros, Fonseca: de las escuelas de gramática medieval al Estudio universitario en Galicia». En En el camino hacia la gloria. Miscelánea en honor de Monseñor Eugenio Romero Pace. Compostellanum. Santiago, 1999, p. 797.

11 Quintana Prieto, Augusto. "Constituciones capitulares de los cabildos españoles del siglo xiII». Anthologica Annua, 1981, vol. 28-29, pp. 484-529.

12 Gujjarro González, Susana. La transmisión social de la cultura en la Edad Media castellana (siglos XI-XV: las escuelas y la formación del clero de las catedrales. Tesis doctoral. Santander: Universidad de Cantabria, ed. en microficha, 1992, vol. 1, pp. 92 y 98. 
teología de las universidades, se restringe al clero de las iglesias colegiales y catedralicias ${ }^{13}$. Es a partir de mediados del siglo XIV cuando las referencias a los docentes de las escuelas de gramática dependientes de los cabildos catedralicios y los contratos orales o escritos de maestros de forma privada comienzan a aparecer de forma esporádica en la documentación eclesiástica y concejil castellana.

\subsection{La regencia de las escuelas de gramática}

El indicio más certero de la existencia de una escuela de gramática que nos proporciona la documentación hasta finales del siglo XIV es la referencia a un maestro, bachiller, lector, repetidor o regente de la cátedra de gramática. Antes de 1350 se han documentado solo para algunas ciudades y villas de la Corona de Castilla. En 1313 para Córdoba, donde el cabildo catedralicio y el obispo nombraban un maestro de gramática para el «Estudio general de gramática» ${ }^{14}$. En Orense aparece un magistro gramatice llamado Fernando en 1312 y a mediados del siglo xv el propio maestrescuela se propuso regentar la escuela de gramática $^{15}$. En Segovia, el bachiller de gramática, Pero Núñez (1325) y el regente de la gramática, Juan de Rivadavia (1344); y, dentro de la misma diócesis, en Sepúlveda, Clemente Sánchez Vercial, leía desde 1387 como maestro de gramática en el «Estudio de la villa», recibiendo de la misma un salario ${ }^{16}$. En la villa de Madrid el concejo sostenía un maestro de gramática para la educación de los hijos de la oligarquía urbana (1346) ${ }^{17}$. En Burgos se puede seguir la secuencia de maestros de gramática desde Sancho González (1354), que formaba parte del grupo de los medio racioneros, con la peculiaridad de que sería el capiscol el encargado de nombrar maestro, ya que la dignidad de maestrescuela, como veremos posteriormente, no se instituyó hasta 1454 por bula de Nicolás $\mathrm{V}^{18}$.

El registro de docentes de las escuelas de gramática es también fragmentario y escaso en la segunda mitad del siglo XIV, dado lo aleatorio de las menciones documentales. En León, Juan de Curueño aparece como bachiller de la gramática en 1366, pero no es hasta

13 Concilio de Valladolid, año 1322; Tejada y Ramiro, Colección de cánones, vol. 3, tít. 21, p. 498: «statuimus ut in qualibet civitate, et in aliis locis insignibus, duobus vel tribus unaquaque dioecesi, ubi, et prout praelatis, considerata dioecesis qualitate et latitudine, videbitur expedire, ponantur magistri in grammatica, qui scholares in dicta scientia instruant, et informent. In civitatibus vero solemniori (solemnibus) magistri in logica depuntentur... Ut autem clerici ad proficiendum in scientia facilius inducatur, statuimus, quod volentes studio literarum insistere, pro tempore quo insistent, eisdem(eidem) fructus beneficiorum suorum usque ad triennium percipiant, aut etiam majori tempore, si hoc praelatis, et suis capitulis expediens videatur».

14 Nieto Cumplido, José Manuel. Historia de Córdoba, II. Islam y Cristianismo. Córdoba: Monte de Piedad y Caja de Ahorros, 1984, pp. 274-275.

15 González García, Miguel Ángel. «La cátedra de gramática de la Catedral de Ourense». Memoria Ecclesiae, 1998, vol. 12, p. 72 (71-82).

16 Calleja Guijarro, Tomás. "Clemente Sánchez de Vercial y el estudio de la gramática de Sepúlveda». Archivos Leoneses. Revista de Estudios y Documentación de los Reinos Hispano-Occidentales, 1988, vol. 83-84, pp. 343-344. pp. 48-52.

17 Castellanos Oñate, José Manuel. «El Estudio de gramática». Madrid Histórico, 2009, vol. 19,

18 Beltrán de Heredia, Vicente. Bulario de la Universidad de Salamanca (1219-1549). III. Salamanca: Universidad de Salamanca, 1967, doc. 1.152, 04/04/1454. 
1460 cuando se encuentra una mención a las casas de las escuelas de gramática que poseía el maestrescuela y arrendaba al regente de dichas escuelas ${ }^{19}$. En Zamora las primeras evidencias datan de 1373, cuando un testigo dice morar en las casas de la escuela de gramática, y de 1394 con la figura del repetidor de las mismas, Juan López. Es posible que a lo largo del xv surgiesen otras escuelas de gramática en la ciudad, pues en 1501 se habla de una escuela en la iglesia de San Cebrián y otra en una antigua sinagoga convertida en iglesia de San Sebastián ${ }^{20}$. En Ávila se documentan dos maestros de la gramática entre 1389-1394 -Fernando Domingo y Pedro Fernández-, pero no se mencionan contratos para el bachiller de gramática que leía en las escuelas hasta 1485, a partir de este momento hasta 1499. Las constituciones de 1495 aportan una valiosa información sobre cómo el estudiante debía pagar una cantidad al bachiller de la gramática ${ }^{21}$. En Cuenca se dona en 1392 un solar situado cerca del postigo de Santa María para levantar las escuelas de gramática, aunque de forma indirecta se sabe de un clérigo que estaba leyendo gramática en la ciudad de Cuenca (1380) ${ }^{22}$. Palencia es una de las pocas sedes episcopales donde se hace referencia a la cátedra de gramática antes del siglo Xv, cuyo regente sería en 1372 Pedro Sánchez de Ventanilla, aunque para la misma fecha se nombra también al maestro de gramática Juan Monis. La ubicación de las escuelas por entonces no se ha documentado, pero en 1440 se hallaban en el camino que iba hacia Valdepeñas ${ }^{23}$.

19 Beltrán de Heredia, Bulario, I, doc. 125, 21/08/1366, p. 406: Rótulo de estudiantes españoles en Aviñón: Juan Alfonso, había regido durante varios años la cátedra de gramática en León. ACL (Archivo de la Catedral de León), Actas capitulares, 1460, n. ${ }^{\circ}$ 9808, fol. 29v: «las casas del maestrescuela pasan a ser poseídas por el bachiller de la gramática».

20 ACZ (Archivo de la Catedral de Zamora), año 1373, Libros de Acuerdos capitulares, leg. 10 bis, fol. 119: «a esto fueron presentes pero ferrandes de carrión, ferrand alfonso que mora en la escuela pero ferrandes bachiller». Juan López, clérigo zamorano y repetidor de las escuelas de gramática, cfr. Beltrán DE HerEdiA, Bulario, I, doc. 298, 01/11/1394, p. 539: Rótulo de expectativas para estudiantes en Avińón. ACZ, Libro manuscrito, año 1501, Caja N. C-Z, fol. 136v.

${ }^{21}$ AHN (Archivo Histórico Nacional), Ávila, Sección Clero, Carpeta 32, n.o 10, ańo 1390: maestro de la gramática, Domingo Fernández. ACAV (Archivo de la Catedral de Ávila), año 1394, Códice 34, fol. 1v: maestro de la gramática, Pedro Fernández. ACAV, Actas capitulares de 1485, fol. 48: bachiller de la gramática Mateo: «En Ávila XXIIII de mayo de LXXXV, estando en su cabildo presente el bachiller Matheo / se obligó a los dichos señores de leer en esta çibdad / de Ávila la cáthedra de gramática leyendo aquello que fuese más provechoso / a los estudiantes y oyentes que oviessen a vista de dos beneficiados de la dicha iglesia deputados por los dichos señores por tres años enteros». AHN, Ávila, Sección Clero, Libro 815, fol. 196v, año 1495: se establece un sueldo de 12.000 maravedíes anuales a cargo de la fábrica de la iglesia para el regente que lea la cátedra de gramática durante tres años. AHN, Sección Códices, 448B, fol. 54v: «los dichos señores deán e cabildo ayuntados a su cabildo general / e con ellos el señor deán dieron la cáthedra al bachiller Amoras el qual la rescibió e se obligó de la servir fasta tres años». AHN, Ávila, Sección Clero, Libro 815, fol. 196v, año 1495: "primeramente que sy algun estudiante fuere al estudio dos o tres días que sea obligado y endosar paga al bachiller de la gramática toda la temporada que sy oviere quinse días y se matriculase sea obligado a pagar».

22 Sánchez Herrero, José. «La actividad educadora, directa e institucional: las escuelas de gramática monásticas y catedralicias». En Bartolomé Martínez, Bernabé (dir.). Historia de la acción educadora de la Iglesia en España. Madrid: Biblioteca de Autores Cristianos, 1995, vol. 1, p. 305.

23 Beltrán de Heredia, Bulario, I, p. 200: Por bula de 12/11/1372 se confiere un canonicato a Pedro Sánchez Ventanilla que llevaba varios años enseñando gramática en el Estudio de gramática de Palencia. ACP (Archivo de la Catedral de Palencia), Actas Capitulares, año 1440, fol. 8: maestro de la gramática Juan Monis. En ACP, año 1460, fol. 56. 
A pesar de lo aleatorio de las evidencias conocidas de maestros de las escuelas de gramática para el siglo XIV, la existencia de las mismas en las ciudades episcopales y en alguna otra villa de la diócesis es evidente. Bien diferente es el número de ellas que había en cada diócesis. De hecho, el obispo y cabildo podían limitarlas, como se ha visto para la diócesis de Ávila donde solo a la villa de Madrigal le estaba permitido tener escuelas ${ }^{24}$. En Córdoba el obispo disfrutaba de la prerrogativa de prohibir que hubiese otro Estudio de gramática en la ciudad, además del subordinado al cabildo catedralicio, de ahí la vigilancia sobre los maestros que enseñaban de forma privada ${ }^{25}$. El paisaje escolar es más variado y complejo en el siglo xv gracias a que la continuidad de la documentación seriada permite establecer registros más sistemáticos de regentes de las cátedras de gramática y sus auxiliares, así como constatar la implicación de los gobiernos municipales en la financiación de los maestros y la fundación desde el mecenazgo privado de escuelas o «Estudios» que sin alcanzar la categoría de Estudios Generales o universidades ofrecían un programa de estudios similar al de las facultades de Artes de las universidades existentes.

Hay suficientes indicios como para afirmar que el número de alumnos creció a lo largo del siglo xv. En una ciudad de señorío episcopal como Palencia se alude únicamente a «las casas de las escuelas» (1460) dependientes del cabildo que eran arrendadas al maestrescuela y que se hallaban ubicadas en la nave de San Bartolomé al lado del hospital de San Bernabé y San Antolín ${ }^{26}$. En los últimos decenios del siglo xv las escuelas debieron trasladarse a la calle que iba a dar al palacio episcopal, abriéndose una de sus puertas a la rúa mayor y la otra a la actual calle de los Estudios. Lo cual podría interpretarse como una señal de apertura a la ciudad y respuesta a una mayor demanda ${ }^{27}$. Pero en 1529 solicitaron al cabildo el retorno a la iglesia y hospital de San Bernabé. Para entonces se habla de un Estudio de gramática, cuyos estatutos revelan un programa de diferentes niveles de enseñanza de la gramática similar al de otros Estudios documentados, como los de Sevilla o Córdoba ${ }^{28}$. Más claro es el caso de Burgos donde la denominación de las escuelas de gramática tomó a mediados del siglo xv el topónimo de la plaza del Sarmental frente a la puerta meridional de la catedral del mismo nombre ${ }^{29}$. El número de casas que albergaban estudiantes, junto con el maestro y sus auxiliares, en 1473 asciende a siete, donde se dice que moraban 280 personas $^{30}$. Algo más tarde, en 1488, se repararon los suelos

24 AHN, Ávila, Sección Clero, Libro 815, fol. 196v, año 1495: «que ninguno sea osado de leer gramatica en Ávila ni en su obispado salvo en este estudio de Ávila e salvo en Madrigal e que sy en otros logares leyere que faga quenta a los bachilleres».

25 Nieto Cumplido, Historia de Córdoba, II, pp. 277-278.

26 ACP, Actas Capitulares, año 1460, fol. 56.

27 ACP, armario VI, leg. 7, n. ${ }^{\circ} 2$, año 1513, fol. 2: «saliendo de la sobredicha casa, yendo por la calle adelante a mano derecha está la casa general del estudio desta çibdat de Palencia. Una puerta principal de arco de piedra con dos puertas [...]. Sobre esta puerta está pintado de figurado de la una parte Sant Nicolás y Santo Domingo y de la otra Prisciano y el Donato, y en medio unas armas [...]. Luego más adelante, a la mesma mano derecha está una casa del general grande con dos puertas a la entrada syn ninguna cerradura, es la entrada de la puerta de arco de piedra, dentro está una cátedra donde se lee la gramática con sus escaleras y asý mesmo seys vigas grandes en que se asientan los estudiantes a oýr».

28 ACP, Libro de Estatutos de 1544, fol. 379.

29 ACB (Archivo Catedral de Burgos), Libro de Registros 15, 18/11/1457, fol. 2.

30 ACB, Libro de Registros 76, 1473, fol. 224. 
«de las casas de la gramática e del general», es decir, de las casas que servían para alojar a los estudiantes y maestros y de la casa donde se impartía docencia ${ }^{31}$. Se trataba ya de un Estudio de gramática de dimensiones considerables dependiente del cabildo catedralicio que permaneció próximo al recinto catedralicio hasta su traslado extramuros al barrio de la Vega a finales del siglo Xvi. A partir de ese momento y bajo el mecenazgo del cardenal Ínigo de Mendoza se convertiría en el colegio de San Nicolás ${ }^{32}$. Hay que subrayar que el traslado se hizo posible tras el acuerdo entre el cabildo catedralicio y el gobierno municipal que fue minando el monopolio clerical sobre las escuelas de gramática. No obstante, la intervención del concejo burgalés sobre la enseñanza de los laicos se testimonia desde finales del siglo XIV (1388 y 1389) cuando, en virtud de un privilegio concedido a la ciudad por Enrique II y confirmado por sus sucesores (Juan I y Enrique III), Burgos dispuso de un maestro de gramática (1.000 mrs de salario) y de un bachiller (200 mrs de salario) ${ }^{33}$. En estos ańos dicho maestro es Juan Velasco, el mismo que aparece como maestro de gramática de las escuelas dependientes del cabildo, lo que sugiere una posible apertura de la institución a los laicos de la ciudad. Algo que puede constatarse en relación con el Estudio de San Miguel de Sevilla durante el siglo Xv, ubicado en casas del cabildo situadas frente a la catedral que disponían de unas 18 cámaras más la casa de general donde se enseñaba. Entre los estudiantes no solo se hallaban mozos del coro catedralicio sino también hijos de la burguesía sevillana que pagaban una iguala al maestro en dinero o en especie. Esto no quiere decir que los propios maestros y bachilleres del Estudio de San Miguel u otros enseñaran además de forma privada en la ciudad ${ }^{34}$. La descripción de las condiciones en las que el maestrescuela de León contrata al bachiller Diego Valdés en 1467 para leer gramática en las escuelas describen la existencia de una casa para el maestro, una cámara con los corredores y otras cámaras que se alquilaban a los estudiantes ${ }^{35}$. Se trata de una estructura de edificio que es o se aproxima al prototipo de colegio que se difundió en Castilla en la segunda mitad del siglo xv y cuyo modelo de referencia había sido el Colegio de San Clemente de los españoles fundado en Bolonia por el cardenal Gil de Albornoz en 1369. En Salamanca las escuelas de gramática o Artes se difuminan al aparecer en la documentación como integrantes del conjunto de la universidad. En 1415 se mencionan unas escuelas de Artes en la calle que va del Desafiadero a San Agustín; no mucho más tarde, en 1421, se arriendan las casas de las escuelas de gramática que estaban cerca de la iglesia de San Vicente con su cátedra y sus bancos y en 1428 negocia para construir escuelas de gramática en unos corrales. En la segunda mitad del siglo XV es posible encontrar referencias a la renta de las casas del corral de la gramática. ${ }^{36}$

31 ACB, Libro de Registros 27, 1488, fol. 385v.

32 López Martínez, Nicolás. "El Colegio de San Nicolás». Boletín de la Comisión Provincial de Monumentos de Burgos, 1930-1933, vol. 3, pp. 9-17.

33 AMB (Archivo Municipal de Burgos), Libro de Actas de 1388, fol. 9 y Libro de Actas de 1389, fol. 19.

34 Sánchez Herrero, José. "El Estudio de San Miguel de Sevilla durante el siglo Xv». Historia. Instituciones. Documentos, 1983, vol. 10, pp. 302-306.

35 Martínez Ángel, Lorenzo, «Instituciones educativas medievales leonesas. La escuela catedralicia». Estudios Humanisticos. Geografía, Historia y Arte, 1996, vol. 18, p. 157.

36 ACSA (Archivo de la Catedral de Salamanca), Actas Capitulares 2, fol. 98v, 20/12/1415: "casas las quales son las que van de Desafiadero a las escuelas de gramática»; Beltrán de Heredia, Bulario, I, año 


\subsection{Financiación de las escuelas y salarios de los maestros}

La financiación de las escuelas y el pago de los salarios de los maestros es un factor determinante para la comprensión de la variedad que fue adquiriendo la organización y titularidad de la enseńanza fuera de las universidades a partir del siglo XIII. En las escuelas de gramática dependientes de los cabildos catedralicios de Castilla durante los siglos XIII y XIV los maestros recibieron un salario proveniente de rentas eclesiásticas de la sede capitular o de la diócesis. La contribución denominada «catedrático» que aportaban las parroquias de la diócesis de Córdoba para el salario del Estudio de gramática en el siglo xIV puede resultar ilustrativa de lo que ocurría en otros lugares ${ }^{37}$. Sin embargo, en algunas villas y ciudades la intervención del poder municipal y real ha dejado huella desde los últimos decenios de la decimocuarta centuria. El concejo de Madrid obtuvo de Alfonso XI en 1346 merced para disponer de una cantidad de 200 maravedíes destinada al salario anual del maestro que enseñase en el Estudio de gramática a los «fijos de los omes buenos» ${ }^{38}$. Es la misma expresión utilizada en relación con el lector de derecho contratado por el concejo burgalés con cargo a la Hacienda real para impartir derecho a los hijos de los oficiales del concejo. Se desconoce si estos hijos de la oligarquía burgalesa acudirían previamente al Estudio o escuela de gramática Sarmental para su aprendizaje básico o lo recibirían de forma privada ${ }^{39}$.

Si comparamos con testimonios del reino de Aragón, en la diócesis de Zaragoza, la provisión de los regentes de los «Estudios de Artes», como los de Teruel o Alcañiz ${ }^{40}$, correspondía al arzobispo o a su vicario, pero tenían en cuenta las propuestas de los prohombres del gobierno municipal. El salario de dichos regentes procedía de las rentas de los arciprestazgos a los que pertenecían los estudiantes, pero el concejo correspondiente podía contribuir con una cantidad para el salario del maestro. En la ciudad de Zaragoza la preocupación del municipio por el Estudio de gramática de la seo se intensifica a partir de 1389, interviniendo en la reforma del edificio de propiedad eclesiástica que lo albergaba ${ }^{41}$.

1421, doc. 90, pp. 667-668; Cartulario de la Universidad de Salamanca I, op. cit., año 1428, doc. 95, pp. 681-682. ACSA, Actas Capitulares 6, fol. 61v, 03/09/1482: «arrendamiento de unas casas que ellos tienen en esta dicha ciudad que son a la collaçión de San Millán que se llaman casas de la gramática». ACSA, Actas Capitulares 8, fol. 1, 02/07/1483: «reparo de las casas que pertenecen al bachiller Ferrandes Nieto que eran de los dichos señores e que están el corral de la gramática».

37 Nieto Cumplido, Historia de Córdoba, II, pp. 277-278: tanto en el Estudio de gramática dependiente del cabildo catedralicio cordobés como en la enseñanza que impartían algunos maestros de forma privada a los estudiantes en sus casas, estos debían pagar una cantidad al maestro.

38 Castellanos Oñate, «El Estudio de gramática», p. 49.

39 AMB (Archivo Municipal de Burgos), Sección Histórica, n. ${ }^{o} 2978$, año 1401: «Yo el Rey fago saber a los mis contadores mayores que por parte del concejo e alcaldes e regidores de la çibdat de Burgos, me fue dicho que en la dicha çibdat avía un lector que leýa en cáthedra de derecho a los filos que los omes onrrados e oficiales della. El lector dise que avía de salario de los reyes onde yo vengo e de mí en cada anno quatro mill maravedíes, segund que dise que la dicha çibdat lo tiene por privilegio. E que me pedían por merced que mandase que lo oviese así de aquí en adelante e le mandase librar el dicho salario».

40 Pueyo Colomina, Pilar. «Documentos sobre maestros en Artes en la diócesis de Zaragoza en la segunda mitad del siglo xIV». Memoria Ecclesiae, 1998, vol. 12, p. 202: la ciudad adquirió terrenos en 1392 para edificar el Estudio de Teruel.

41 Blasco Martínez, Asunción. «El Estudio de Artes en Zaragoza (siglos XIV-Xv)». Memoria Ecclesiae, 1988, vol. 12, p. 258. 
En Sepúlveda, diócesis de Segovia, Clemente Sánchez Vercial, maestro que regía el Estudio de gramática, recibía en 1387 su salario del concejo a cargo de la renta anual de la pregonería que la reina Leonor había concedido a la institución municipal para tal $\mathrm{fin}^{42}$. Tras este maestro, cuya trayectoria puede seguirse al convertirse posteriormente en arcediano de Valderas y como autor de algunas obras conservadas, se tiene noticia de la contratación por tres años como lector de gramática de Ruy García ${ }^{43}$. Debió ser común que estos contratos fuesen orales.

En la misma diócesis de Segovia se documentan otros dos centros de enseñanza de tipología diferente en cuanto al origen, aunque tienen en común la intervención del poder municipal. El primero es un «Estudio de Artes» fundado por Gómez González, arcediano de Cuéllar, quien en 1424 ordenó comprar unas casas en dicha villa para ubicar en las mismas unas escuelas junto con un hospital. Dicho complejo, así como el salario del maestro, sería financiado con las rentas derivadas de préstamos y raciones que el arcediano poseía en la diócesis de Burgos. De hecho, un año más tarde consiguió la confirmación de los préstamos que tenía asignados en 21 lugares del obispado para destinarlos a tal empresa ${ }^{44}$. La reforma de las casas de la escuela en 1438 describe una arquitectura escolar que toma el modelo anteriormente referido de colegio que inauguró el Colegio de San Clemente de los espańoles de Bolonia (1364) con capacidad para 200 escolares $^{45}$. Aunque la dirección de la institución fue asumida por los cofrades del hospital, el interés del concejo de Cuéllar por intervenir en la misma se plasma en una contienda que tuvo lugar en 1437 entre cofrades y regidores municipales que se saldó en favor del concejo. A partir de ese momento, asumió la administración del Estudio y del Hospital ${ }^{46}$.

El segundo de los centros aludidos se benefició, sin duda, de la elección de Segovia como residencia de la corte del rey Enrique IV, quien en 1466 concedió a la ciudad privilegio de fundación de un Estudio de gramática, lógica y filosofía que sería posteriormente

42 Calleja Guijarro, "Clemente Sánchez de Vercial», pp. 342-347.

43 Sáez, Emilio. Colección diplomática de Sepúlveda. Segovia: Diputación Provincial de Segovia, 1961, vol. 1, doc. 68, año 1393: «Dońa Leonor, por la graçia de Dios, reina de Navarra e condesa de Evreux, al concejo, e alcaldes e alguazil e regidores de la mi villa de Sepulvega, que agora son e seran daqui en adelante salud e graçia. Sepades que paresçio ante mi Ruy Garçia, lector de la gramatica en la dicha villa, e me dixo que vos el dicho concejo e regidores, que dierades los derechos de la pregoneria a Clemente Sanchez, porque leyese ende gramatica, e eso mesmo estos annos pasados el dicho Ruy Garçia, e quanto leyó. E commo quier que el esta presto para leer la dicha sçiençia en ende en la dicha mi villa, diz que vos, los dichos regidores, que le quitastes e le mandaste quitar los derechos de la dicha pregoneria, por lo qual el dicho Ruy Garçia me dixo que si oviese a pasar que el no leeria en la dicha sçientia e pidiome por merçed que le proveyese de remedio e derecho».

44 Ibídem, doc. 216, título 1 y título 7 , año 1424

45 Ibídem, doc. 255, año 1438, p. 599: «[...] e porque de bien en mejor se pueda multiplicar, e los ignorantes e pobres sean enseñados, por ende ordeno que las casas donde está de presente o se, que son propias, cabe la iglesia de San Gil de la dicha villa que se reparen e reformen cada anno, e las paredes se fagan de cal y canto, todas con su claustra en medio e cámaras derredor, a manera de colegio, con su general e otros complimientos, donde puedan estar fasta doszientos escolares».

46 Ibídem, doc. 255, año 1437, pp. 591-592: «[...] los señores concejo, regidores, cavalleros, escuderos, omnes buenos de la villa de Cuéllar e su tierra, todos avenida, justamente, avida su deliberaçión concordablemente, otrossí a instancia e pedimiento de fray Gómez [...] tomaran e toman en su regimiento e administraçión perpetuas el Ospital nuevo de Santa María Magdalena e el Estudio en la dicha villa fundados por el dicho arcediano $[\ldots] »$. 
confirmado por los Reyes Católicos (1482) y por la reina Juana (1508). Podría calificarse de «Estudio particular», siguiendo la definición del código de las Partidas ${ }^{47}$, pues nunca llegó a convertirse en Estudio General o universidad. La provisión real no debe ocultar el papel que jugó el prelado Juan Arias Dávila en este proceso, pues accedió de facto a la sede episcopal de Segovia precisamente en 1466. El obispo tenía «Estudio» en las casas del palacio episcopal y convocó, entre otros, el famoso sínodo de donde salió el Sinodal de Aguilafuente, primer libro impreso en los reinos hispanos ${ }^{48}$. Para su financiación Enrique IV concedió 38.000 maravedíes procedentes de rentas de alcabalas de ciertos lugares de Segovia y de tercias de ciertas parroquias, es decir, rentas reales y eclesiásticas, cuya recaudación y asignación debería estar supervisada por el obispo de Segovia ${ }^{49}$.

Los dos últimos decenios del siglo xv, animados por el espíritu de reforma espiritual e institucional y por los ideales del humanismo teológico que floreció en los ambientes académicos universitarios castellanos, asistieron al nacimiento de los primeros colegiosestudio. Entre los primeros, se encuentra el Colegio de San Antonio de Portaceli en Sigüenza que fundara el canónigo y arcediano Juan López de Medina, perteneciente al círculo de protegidos del cardenal Pedro González de Mendoza a finales del siglo xv. Su origen está en la creación de un convento franciscano en Sigüenza a partir del buleto expedido por monseńor Nicolao Franco en 1476. Se asignaron al mismo tres cátedras y unos ańos después el cardenal Mendoza daba facultad al colegio para redactar sus propias constituciones. Estos son los cimientos de la institución educativa que en 1485 instituyó y edificó Juan López de Medina impelido por el movimiento de reforma espiritual y eclesiástica que recorría los reinos peninsulares. Las constituciones del colegio que presentó al cabildo en este año hacían de la formación del clero un imperativo ineludible. Tras su fallecimiento en 1489, el colegio fue elevado a la categoría de Universidad, estando dotado en estos momentos de una cátedra de teología y una de Artes, a la que el cardenal Mendoza añadió una de derecho (Decretos) $)^{50}$.

En Santiago no fue un eclesiástico, sino el notario y regidor municipal, Lope Gómez de Marzoa, quien proyectó un colegio-estudio en el que estudiasen clérigos sin recursos y otros estudiantes pobres. De este modo, nació en 1495 el Estudio compostelano que sentó los cimientos de la futura universidad. El regidor Marzoa dotó el colegioestudio con sus bienes. Sin embargo, al carecer de descendientes que asegurasen la continuidad de la institución confió la misma a fray Juan de Melgar que desde 1493 regía el monasterio de San Martín de Pinario. A partir de entonces los abades de este monasterio reformado, que había sido incorporado a la Congregación de San Benito de Valladolid,

47 Las Siete Partidas del Rey Alfonso X, ed. de la Real Academia de la Historia. Madrid: Imprenta Real, 1807, Partida II, título XXXI, ley I: «quiere tanto decir como cuando algunt maestro amuestra en alguna villa apartadamente a pocos escolares; e tal como este puede mandar perlado o conceo de algunt lugar».

48 Sanz González, Mariano. "La reforma de la Iglesia en los sínodos de Juan Arias Dávila». En Galindo García, Ángel (ed.). Arias Dávila: obispo y mecenas. Segovia en el siglo XV. Salamanca: Universidad Pontificia de Salamanca, 1998, pp. 419-422.

49 Publicado en Estudios Segovianos, 1951, vol. 3, apéndice, pp. 234-246.

50 Chacón Gómez-Monedero, Francisco A. «La biblioteca de don Juan López de Medina, fundador del Colegio-Universidad de San Antonio de Portaceli de Sigüenza». Wad-al-Hayara: Revista de Estudios de Guadalajara, 2003, vol. 30, pp. 313-348. 
LAS ESCUELAS DE GRAMÁTICA EN LA CASTILLA BAJOMEDIEVAL (SIGLOS XIII-XV)

SUSANA GUIJARRO GONZÁLEZ

adquirieron el patronato del colegio-estudio que abrió sus puertas a estudiantes de lo que había sido el reino de Galicia. El colegio se instaló en la abadía de Antealtares que en 1487 había sido suprimida por Inocencio VIII e incorporada al monasterio de Pinario. De ahí, que el colegio tomase el nombre de San Gregorio de Antealtares. Un caso peculiar en que una comunidad benedictina es sustituida por una comunidad escolar que ofrecía celdas y aulas. Funcionó como un Estudio de gramática y Artes regentado por un bachiller en Artes $^{51}$.

\subsection{La provisión de la Cátedra de gramática en las ciudades castellanas}

Otro aspecto de interés a considerar en relación con las escuelas bajomedievales es la provisión de la cátedra de gramática, proceso no exento de tensiones entre los candidatos y sus promotores o protectores. El caso más emblemático conocido hasta ahora es el de la provisión del maestro regente de la escuela de gramática de Burgos que se enmarca en un dilatado conflicto que se prolongó desde 1468 hasta 1472. A diferencia de lo ocurrido en el resto de las actuales catedrales castellanoleonesas, la figura de maestrescuela como dignidad no fue introducida en el cabildo hasta mediados del siglo xv. El papa Nicolás V (1447-1455) otorgó en 1454 una bula de institución de la maestrescolía a los cabildos catedralicios de Burgos y Calahorra ${ }^{52}$. Hasta 1456 la documentación catedralicia burgalesa no registra la presencia de la figura del maestrescuela entre sus miembros. Anteriormente y hasta finales del siglo xIV el capiscol o chantre ejercía las funciones propias del maestrescuela (nombrar maestro de gramática, entre otras). A partir de este momento pueden datarse maestros y bachilleres de la gramática nombrados por el cabildo para regir las escuelas. Para ocupar la maestrescolía instituida en Burgos en 1454, se nombró al racionero Alfonso López de Béjar quien, al mismo tiempo, disfrutaba del arcedianato de Béjar en la diócesis de Plasencia ${ }^{53}$. A pesar de que la bula de institución incluáa la anexión de una canonjía a la dignidad del maestrescuela, las dos canonjías que quedaron vacantes en 1461 fueron proveídas a dos candidatos defendidos por el cabildo burgalés ${ }^{54}$. No hay constancia, de hecho, de que obtuviera una canonjía hasta 1477. La primera gran disputa que el maestrescuela López de Béjar mantuvo con el cabildo fue precisamente debida a la primera de las canonjías que vacaron, la que había ocupado Juan de Velasco y llevaba anejos préstamos del arcedianato de Palenzuela. En agosto de 1468, sin que este conflicto estuviera aún resuelto, se abrió otro prolongado conflicto relativo a la administración de las escuelas de gramática. El maestrescuela demandó al maestro de la gramática, Juan González de Santamaría, la administración de dichas escuelas junto con las rentas y frutos anexos a las mismas y le amenazó con promulgar una sentencia de excomunión

51 López Alsina, «Marzoa, Melgar, Muros, Fonseca», pp. 800-807.

52 Beltrán de Heredia, Bulario, III, doc. 1.152, 04/04/1454: institución de la maestrescolía en la Catedral de Burgos; y doc. 1.158, 31/12/1454: institución de la maestrescolía en la Catedral de Calahorra.

53 Beltrán de Heredia, Bulario, III, doc. 1.152, 04/04/1454.

54 ACB, Libro de Registros 16, fols. 252v-253, 06/05/1461: canonjía ocupada por Juan Arias. ACB, Libro de Registros 16, fol. 274v, 21/08/1461: canonjía proveída a Juan de Lucena. 
si no abandonaba el puesto en seis días. El cabildo alegó, enfatizando los criterios de antigüedad y costumbre, que era competencia suya el nombramiento de maestros que enseñasen en las escuelas y que el beneficio eclesiástico anexo al cargo de administrador de las escuelas era perpetuo. Insistieron en que el maestro González de Santamaría había regentado las escuelas durante 28 años. Adujeron, además, como argumento legal que una bula de Calixto III (1455-1458) había revocado la bula de su antecesor Nicolás V (1447-1455) de anexión de préstamos y de una canonjía a la maestrescolía, así como a la canonjía de la escuela ${ }^{55}$. El maestrescuela intentó sin éxito también desposeer de su canonjía al bachiller de Montealegre que la ocupaba desde hacía trece años ${ }^{56}$.

Dos meses más tarde, en octubre de 1468, fallecía el maestro de la gramática Juan Sánchez de San Martín y se abría un proceso que nos informa de las fases que conllevaba la provisión de las cátedras de gramática de las escuelas. Primeramente, se publicaban cédulas en las universidades para dar a conocer la vacante a posibles candidatos. En este caso se presentaron tres candidatos a la oposición. De los tres, el bachiller Juan de Aguilar tenía el apoyo del obispo Acuña. El capiscol tuvo un protagonismo especial en la provisión que finalmente recayó en el bachiller citado. Obviamente, el maestrescuela protestó airadamente recordando que pertenecía a su dignidad el proveer la cátedra de gramática. Esta reivindicación por parte del maestrescuela se prolongó hasta 1472, momento en el que renunció a las competencias que su dignidad tenía en otras catedrales. Desde finales de 1468 hasta entonces mediaron sucesos graves que implicaron a los poderes laicos de la ciudad, el tenente del castillo y el concejo de Burgos. La fase de mayor tensión se produjo entre 1470 y 1471, cuando con el apoyo del obispo Acuña, del que era entonces vicario, reclamó beneficios y préstamos que a su parecer eran debidos a su dignidad y privó de los mismos a algunos beneficiados. Hecho que desencadenó el encarcelamiento del maestrescuela y la injerencia del tenente del castillo y los regidores municipales a los que López de Béjar recurrió, al tiempo que el obispo Acuña entraba en la confrontación. La privación de libertad durante un tiempo no impidió al maestrescuela, haciendo uso de sus facultades jurisdiccionales, promulgar cartas de excomunión contra varios miembros del cabildo. El cabildo frenó la lectura de las cartas de excomunión por clérigos o notarios, a lo cual el maestrescuela reaccionó acudiendo al alcaide del castillo para que hiciese leer y cumplir las referidas cartas de excomunión. El que llevase un conflicto eclesiástico a la justicia civil fue la gota que colmó el vaso de la contienda. El cabildo le encarceló nuevamente y pidió al protonotario merced para llevar el caso a Roma. El siguiente y último paso fue el arrepentimiento del maestrescuela López de Béjar que llevaba implícita su renuncia definitiva a la reclamación de más de las dos prebendas que disfrutaban las otras dignidades y de la regencia de la escuela de gramática ${ }^{57}$.

55 ACB, Libro de Registros 18, fol. 145, 12/08/1468.

56 ACB, Libro de Registros 18, fols. 150 y 155, 12/08/1468.

57 Para un estudio más detallado de este conflicto entre el maestrescuela y el cabildo de la Catedral de Burgos, véase Gujjarro González, Susana. "Antigüedad, costumbre y exenciones frente a innovación en una institución medieval: el conflicto entre el maestrescuela y el cabildo de la Catedral de Burgos (14561472)». Hispania Sacra, 2008, vol. 60, n. ${ }^{\circ}$ 121, pp. 83-92. 
LAS ESCUELAS DE GRAMÁTICA EN LA CASTILLA BAJOMEDIEVAL (SIGLOS XIII-XV)

SUSANA GUIJARRO GONZÁLEZ

La provisión de la cátedra del Estudio de gramática de Palencia sin que se produjera conflicto alguno en 1501 detalla el procedimiento de la provisión que debió ser común durante el siglo xv. En este caso el cabildo y el maestrescuela comisionaron a dos miembros del cabildo, el licenciado Gregorio del Castillo (magistral de la Catedral) y el licenciado Luis del Puerto. El trámite se inició con la orden de poner un edicto en las iglesias y universidades de Salamanca y Valladolid, donde se informaba sobre la vacante y provisión de la cátedra. Transcurridos 30 días del edicto, se presentaron 10 opositores de dentro y fuera de la diócesis de Palencia. Tras lo cual se procedió al sorteo del orden y fecha de intervención de cada uno de ellos, asignándoles las tres lecciones que debían ser convencionales en estas pruebas: una sobre la gramática de Antonio de Nebrija, otra sobre Virgilio y una tercera sobre el prólogo de San Jerónimo a la Biblia. El opositor debía abrir el libro por tres partes, eligiendo una de ellas como tema de su lección, una vez finalizada la misma el resto de los opositores debían «argumentar honestamente» con él sobre lo expuesto. Es interesante destacar cómo uno de los opositores preguntó cuál sería el salario del catedrático de gramática y si este puesto era perpetuo, además de argumentar que "él no tenía quien le favoreciese, ni conocía a nadie en esta tierra " ${ }^{58}$. A pesar de la insistencia en la suficiencia y moralidad de los candidatos en la formulación de las actas, este elocuente testimonio de uno de ellos desvela la importancia de las redes de patronazgo y clientelismo en estas provisiones oficialmente abiertas.

\section{El CURrículum de las escuelas de gramática y los STUdia HUMANitatis}

El programa y el método de enseñanza de las escuelas de gramática o de Artes entre los siglos XIV y XV son aún poco conocidos en la historiografía europea medieval en general y en la hispana en particular. Los mejor conocidos son los de las escuelas italianas enclavadas en paradigmáticas ciudades del humanismo. Las investigaciones sistemáticas de manuscritos conservados y de inventarios de bibliotecas bajomedievales tanto por filólogos como por historiadores han permitido este avance. No obstante, persiste el debate sobre la diferencia entre un currículum que Eugenio Garín (1957) denominó medieval ${ }^{59}$ y un currículum humanista que se habría implantado de forma desigual durante el siglo XIV. En las últimas cuatro décadas algunos estudios han matizado esta nítida diferenciación en relación con las escuelas italianas. Partiendo del análisis de manuscritos escolares e inventarios de bibliotecas relacionados con la enseñanza de las escuelas de gramática, unos proponen una evolución gradual de la pedagogía medieval a la humanista de la gramática y la retórica en los siglos XIV y XV, cuando los gramáticos más clasicistas trataban de introducir un nuevo latín acorde con las necesidades de las oligarquías urbanas y los nacientes Estados modernos ${ }^{60}$. Otros defienden que no hubo una ruptura entre una antigua pedagogía medieval y una humanística a comienzos del siglo xv, período vital

58 ACP, Actas Capitulares de 1501-1510, fols. 30v-32.

59 Garin, Eugenio. La educación en Europa. 1400-1600. Barcelona: Crítica, 1987.

60 Grafton, Anthony y Jardine, Lisa. From Humanism to the Humanities. Education and the Liberal Arts in Fifteenth-and Sixteenth-Century Europe. Cambridge-Massachusetts: Harvard University Press, 1986. 
de la segunda generación de humanistas, afirmando que la tradición monástica de la gramática moralizante persistía en el siglo xIv. De tal modo que el aprendizaje de latín tenía como fin primordial transformar el interior de la person ${ }^{61}$. Argumento este último rechazado también en base al análisis de glosas y comentarios presentes en manuscritos de uso escolar que demostrarían una enseñanza de la gramática en sus niveles elemental y medio abrumadoramente filológica más que moralizante ${ }^{62}$.

Debates historiográficos aparte, lo cierto es que en las escuelas italianas la propuesta educativa del humanismo era bien perceptible dos décadas antes de mediados del siglo Xv. Es la franja temporal en que el currículum escolar conocido como los Studia humanitatis cobró vida haciendo del dominio del lenguaje y el diálogo directo con los autores de la Antigüedad clásica los pilares de dicho currículum. Metodológicamente, estos cometidos se tradujeron en un enfoque filológico e histórico de los autores clásicos y medievales manejados. Triunfó el interés por contextualizar históricamente las propuestas y doctrinas que ofrecían dichas obras y autores. Esta cronología de introducción de las ideas pedagógicas del humanismo no es ajena a lo que sucedía en los reinos hispanos. En las cortes reales, tanto de Juan II (1405-1454) en Castilla como de Alfonso V (1356-1458) en Aragón, se hallaban presentes humanistas. En Castilla, en concreto, se trataba de autores vinculados a la Universidad de Salamanca, en cuya formación o enseñanza se advierten rasgos de un humanismo temprano. Lope de Barrientos (1382-1469) escribe sobre la fortuna, Alfonso de Cartagena (1384-1456), obispo de Burgos, tradujo el De inventione de Cicerón; Alfonso de Madrigal (1401-1455), maestro de filosofía moral en Salamanca, compuso sus Cuestiones de filosofía moral a partir del libro segundo de la Ética de Aristóteles; y el también catedrático de la misma materia, Pedro de Osma (1430-1480), disertaba sobre un aristotelismo enriquecido con aportaciones filológicas ${ }^{63}$.

¿Qué puede decirse de los programas de las escuelas de gramática castellanas con relación a la influencia de los Studia humanitatis? La primera dificultad para ofrecer una respuesta sólida a esta cuestión es la falta de estudios sistemáticos de manuscritos que contengan obras de uso escolar como los realizados para las escuelas italianas. Las ediciones críticas de gramáticas medievales o de obras de diferentes géneros escritos que pueden relacionarse con la enseñanza por filólogos o historiadores de la literatura medieval no son abundantes. De ahí que, hasta el momento, los inventarios de bibliotecas se hayan utilizado como fuente indirecta para deducir los posibles usos escolares de las obras contenidas en los mismos. Otra fuente inevitablemente parca es la propia denominación de las escuelas o "Estudios de Artes» y de gramática documentados. Comenzando por esta

61 Genl, Paul F. A Moral Art. Grammar, Society and Culture in Trecento Florence. Ithaca-New York: Cornell University Press, 1993.

62 BLACK, Robert. Humanism and Education in Medieval and Renaissance England. Tradition and Innovation in Latin Schools from the Twelfth to the Fifteenth Century. Cambridge: Cambridge University Press, 2001.

63 Delgado Jara, Inmaculada y Herrera García, Rosa María. «Humanidades y humanistas en la Universidad de Salamanca en el siglo XV». En Rodríguez-SAn Pedro Bezares, Luis E. y Polo Rodríguez, Juan Luis (eds.). Salamanca y su Universidad en el primer Renacimiento. Siglo XV. Salamanca: Universidad de Salamanca, 2011, pp. 253-264. 
última y como se ha confirmado para las escuelas francesas ${ }^{64}$, algunas, sobre todo las calificadas como "Estudios de Artes», ofrecían un programa que cubría no solo la gramática latina propiamente dicha sino también la retórica, la lógica y la filosofía moral.

En Sevilla, el frustrado Estudio General que fundara Alfonso X en 1254 se describe como "Estudio de latín y árabe» en atención a la preocupación existente por armarse doctrinalmente contra los adversarios de la fe cristiana, conociendo su lengua y tratados. El interés por la lengua es diferente al del Estudio bajomedieval de San Miguel calificado simplemente como escuela de gramática. En el mismo enseñaban un maestro de la gramática y un bachiller repetidor. En la descripción de las 18 cámaras que integraban las casas de las escuelas, se distinguen dos de mayor tamaño destinadas a la docencia, el «General mayor» y el «General menor». No es descabellado pensar que esta división espacial pudiera corresponderse con dos de los niveles del currículum de las escuelas bajomedievales, el de los menores y el de los mayores, donde se supone habría tres niveles de enseńanza de la gramática latina. Puede que los estudiantes del nivel menor y medio acudieran al "General menor». Era en el nivel medio y superior donde obras de contenido moral servían para avanzar en el dominio de la gramática y del resto de las Artes del Trivium $^{65}$. Por tanto, como se hace ver claramente en la denominación del Estudio fundado en Segovia por Enrique IV, la lógica forma parte esencial del programa ${ }^{66}$. Lo mismo que en el Estudio de gramática, lógica y filosofía (se refiere posiblemente a filosofía moral) de Córdoba, aunque en el Estudio de Daroca, en Aragón, se habla de la existencia de maestros en Artes, lógica y «natura», es decir, filosofía natural que no era otra cosa que la Física de Aristóteles ${ }^{67}$. En Santiago también el cabildo catedralicio prescribía que los beneficiados fuesen a aprender lógica y gramática ${ }^{68}$. En la Catedral de Sigüenza, el prelado Gonzalo de Aguilar fundó la cátedra de gramática y lógica en 1343, dotándola con 600 morabetinos de moneda corriente. La fundación contemplaba también la enseñanza de canto llano y órgano para los mozos del coro $^{69}$. En la villa burgalesa de Briviesca se documenta un "maestro del Catón», curioso apelativo que ilustra sobre el uso de los Disticos de Catón ${ }^{70}$. Bajo el epígrafe de gramática cabe igualmente la retórica, especialmente alguna de sus ramas, cual es el arte de componer en prosa y en verso. La importancia que la poesía adquiere en el currículum de los Studia humanitatis se percibe en la denominación de las escuelas o «Estudios» documentados: el Estudio de gramática, lógica y poesía

64 Caesar, Mathieu. "Écoles urbaines, pouvoir municipal et éducation civique à la fin du Moyen Âge. Quelques observations à partir du cas genevois aux XIV $-\mathrm{XV}^{\mathrm{e}}$ siècles». Histoire Urbaine, 2011, vol. 32, p. 164.

65 Sánchez Herrero, «El Estudio de San Miguel de Sevilla», pp. 303-304.

66 Privilegio de Enrique IV por el que se funda en Segovia un Estudio de gramática, lógica y filosofía en 1466, al que dota con 38.000 maravedís de juro de heredad cedidos de la renta de alcabalas y de las parroquias de varios lugares. Publicado en revista Estudios Segovianos, 1951, apéndice, pp. 234-236.

67 Nieto Cumplido, Historia de Córdoba, I, pp. 274-275. Falcón Pérez, Ledesma Rubio, OrcásTegui Gros y Sarasa Sánchez, «Las universidades del reino de Aragón», p. 90.

68 López Alsina, «Marzoa, Melgar, Muros, Fonseca», p. 797.

69 Minguella y Arnedo, Toribio. Historia de la diócesis de Sigüenza y de sus obispos. Vol. 2. Colección diplomática. Madrid: Imprenta de la Revista de Archivos, Bibliotecas y Museos, 1901-1913, doc. 97, p. 530. Es un dato que ha de tomarse con cautela pues el autor incorpora la fuente de procedencia.

${ }_{70}$ ACB, Libro de Registros 4, fol. 162, 26/06/1391: Ruy Gutiérrez de Briviesca, maestro del Catón. 
de Madrid $^{71}$; en Tuy la cátedra de gramática y poesía ${ }^{72}$ mencionada en el sínodo de 1528 debió existir ya en los últimos decenios del siglo xv; y en León se contrató un doctor italiano en 1498 al que se le pagarían 8.000 maravedíes, informando al mismo tiempo de que en la villa de Mayorga se le pagaban 15.000 maravedíes, una clara manifestación de la influencia de la pedagogía humanista ${ }^{73}$. En la oposición para proveer la cátedra de gramática de Palencia (1501), de la que se ha hablado anteriormente, a los opositores se les asignó como lectura al poeta Virgilio, además del prólogo de San Jerónimo sobre la Biblia y la gramática de Antonio de Nebrija ${ }^{74}$.

Aunque se trata de unos estatutos del Estudio de gramática palentino de fines del siglo XVI (1570), sirven para corroborar algunas características de la organización de la enseńanza y de su contenido que se habían esbozado ya a lo largo del siglo xv. En primer lugar, la división de los alumnos en niveles de aprendizaje, distinguiéndose entre mayores, medianos y menores (separados también aquí de los mínimos) ${ }^{75}$. El catedrático y regente del Estudio debería tener tres repetidores latinos y versistas. Catedrático y repetidores leerían cuatro lecciones (dos en la mañana y una en la tarde), excepto el repetidor de medianos que leería tres lecciones desde octubre hasta el 24 de junio. Desde el día de San Juan hasta el día de Santiago el catedrático leería sólo 2 lecciones, una en la mańana y dos en la tarde. Más interesante es comprobar la importancia del método didáctico de la disputa o debate. En este ejercicio el maestro, una vez hecha matrícula de sus estudiantes, formaría dos bandos que se colocarían en lados opuestos de los bancos superiores del aula. Cada bando elegiría una cabeza de 10 estudiantes, entre los cuales habría un capitán y otros subalternos a imitación de la jerarquía militar. Ante los puntos a debatir con mayor dificultad presentados por el maestro, los miembros de esta cabeza serían los primeros en acusar, corregir y provocar a los del bando contario. Por supuesto, maestros y estudiantes deberían hablar en latín ${ }^{76}$. El debate como método de

71 Castellanos Oñate, «El Estudio de gramática», pp. 48-52.

72 Sínodo de Tuy, año 1528; Bernal Palacios, Arturo. Synodicon Hispanum I. Galicia, García y García, Antonio (dir.), op. cit., p. 493.

73 ACL, Actas Capitulares, año 1498, n.o 9834, fol. 2v.

74 ACP, Actas Capitulares, año 1501-1510, fol. 30v: «[...].en lo que declararon el orden siguiente que a cada uno dar esta ora de las onze que se le asignasen tres leçiones, una en el arte de Antonio Nebrixa y otra en el Virgilio y otra en un prólogo de San Jerónimo sobre la Biblia abriendo en cada libro por tres partes y esogiendo el que avía de leer lo que fisiese no dando a uno lo que otro oviese leýdo y acabando el uno de leer todos los otros que quisiesen le pudiesen argüir onestamente sobre su leçión e el que más diestro y suficiente destos fuese visto levase la dicha cáthedra e desta manera fue el primero a quien primero salió la suerte».

75 ACP, Armario IV, Leg. 2, n. ${ }^{\circ}$ 68, año 1570: «Cap. 2. Que nuestro cathedrático distribuya todos sus estudiantes en quatro clases, la primera será de mínimos, la segunda de menores, la tercera de medianos y la quarta de mayores y nuestro cathedra buenos latinos y que sepan haçer versos porque en todo puedan platicar y ordenamos que el nombramiento dellos haga nuestro cathedrático de consejo de nuestros visitadores».

76 ACP, Armario IV, Leg. 2, n. ${ }^{\circ}$ 68, año 1570, fols. 3v-4r: "Cap. 6. Que el maestro de cada clase haga dos bandos y eliga magnates y decuriones para que unos a otros se provoquen y aya competencia. En todos los exercicios loables importa mucho la emulación y competencia. Por tanto, ordenamos que al principio de curso aviendo venido los estudiantes forasteros cada maestro en su aula haga matrícula de sus estudiantes y en los asientos formará dos bandos unos opuestos a los otros en los bancos superiores, un sargento y 1,2 o 3 decuriones y más lo que pidiere el número de aquella classe reduçido a decurias para que cada cabeza de los sobredichos tenga a su cargo diez estudiantes que su maestro les señalare y dellos le dará quenta quando no 
desarrollo de las preguntas y la argumentación se aviva al representarlo en un escenario de competición entre bandos, exaltando la memorización del conocimiento como sustrato imprescindible del progreso de aprendizaje $\mathrm{e}^{77}$.

El estatuto prescribía, además, los manuales o autores que deberían leer en las horas determinadas los repetidores de mínimos, menores y medianos, así como el catedrático. Una información que revela la utilización de autores y manuales de gramática que habían estado presentes en las décadas finales del siglo xv en el currículum escolar. La gran diferencia es la omnipresencia de la gramática de Nebrija como manual base de la enseñanza gramatical. El repetidor de mínimos debería leer cada día cuatro lecciones, siguiendo la gramática de Nebrija sobre declinaciones, conjugación de verbos, composición y partes de la oración. El repetidor de menores, además de continuar con la sintaxis y morfología, leerá las fábulas de Esopo, obra habitual en las escuelas italianas bajomedievales y les guiará en la memorización de una obra de la época (los Diálogos de Luis Vives sobre la educación del príncipe, cuya intención es instruir en la lengua latina al mismo tiempo que introducir cuestiones sobre la conducta moral). El repetidor de medianos leería en la lección de la mañana sobre obras de Ovidio y en las dos de la tarde sobre las de Cicerón. Por su parte, al catedrático se le asignarían dos lecciones por la mañana sobre Virgilio, Horacio y el Libro IV de la gramática de Nebrija, los alumnos aventajados deberían componer en verso. En la tarde leería sobre obras de Suetonio y Valerio, además de sobre prosodia, siguiendo el Libro IV de la gramática de $\mathrm{Nebrija}^{78}$. El componente moral de este

recitaren de memoria o no vinieren a leçión o faltaren a sus obligaciones y a estos magnates se cargará mayor obligaçión declarar los puntos más dificultosos que los maestros preguntaren y serán los primeros en acusar, corrigir y provocar a cáthedras a los del bando contrario de su classe y en terminaçión de las cargas serán honrrados con los superiores alientos de su bando pero si alguno dellos no luçiere o desmereçiere su maestro le depondrá y porná otros en su lugar».

77 ACP, Armario IV, Leg. 2, n. ${ }^{\circ}$ 68, año 1570, fol. 5r: «Cap. 9. [...] por la tarde y en la segunda lecçión de cada sábado por la tarde nuestro cathedrático y el repetidor de medianos cada uno en su aula proveerá una cáthedra por examen y concurso público entre dos estudiantes que de un bando contra otro se ayan provocado el sábado atrás a esta misma hora y les señalará un passo conveniente a su capacidad dando a cada uno a solas medio quarto de hora para que le mire y a quien mejor le declarare en la cáthedra honrrará y dará el premio propuesto y acabado este exerçicio con el aplauso de la victoria mandará que salga el que quisiere a desafiar a otro del bando contrario para el sábado siguiente y en este mismo tiempo y hora y a este mismo modo tanbién los mínimos y menores en sus aulas ternán sus desafíos saliendo uno contra el otro del bando contrario con preguntas y argumentos sobre los que ubieren oýdo porque esta competencia traerá muchos provechos y porque tanto más sabe el estudiante quanto más aprende y sabe de memoria y no es menor virtud guardar y conserbar lo ganado que adquirir de nuevo, ordenamos que todos los maestros cada sábado quando releyesen los libros que ban leyendo y sus estudiantes aprendiendo de memoria les amonesten que todo quanto ubieren aprendido de memoria en los años de atrás así de los libros del arte de Antonio Nebrija como de los poetas y proverbios y phrases elegantes cada mes tengan costumbre de repetirlo una o más veçes».

${ }_{78}$ ACP, Armario IV, Leg. 2, n. ${ }^{\circ}$ 68, año 1570, fol. 3r: «Cap. 5. El repetidor de la tercera clase de medianos en la primera leçión de la mañana leerá las epístolas o otra obra de Ovidio y variará cada ańo y los medianistas las mandarán a la memoria y las reçitarán el día siguiente antes de la primera leçión de la mañana y en la primera lecçión de la tarde leerá la epístola de Ciçerón o otra obra del mismo autor y variará cada año y en la segunda y última de la tarde tomará quenta a su clase de la leçión que uberen oýdo por la mañana a nuestro cathedrático del libro quarto de la syntasxi y hará exerciçios y dará oraciones por ella. Nuestro cathedrático en su aula en la primera lecçión de la mańana leerá el libro que le pareçiere de Virgilio o Oraçio y cada año variará y este libro mandarán a la memoria los mayoristas y le reitarán la mañana siguiente a su maestro o 
currículum no se advierte solamente en las lecciones éticas que extraen de estos autores, a la vez que se entregan al método filológico e histórico, sino también en el conocimiento de la doctrina cristiana que ocuparía la actividad del catedrático los sábados, reuniendo a todos los estudiantes en el aula mayor y platicándoles sobre los elementos fundamentales de dicha doctrina ${ }^{79}$.

Si de las denominaciones que recibían las escuelas de gramática o de Artes en la Baja Edad Media se pasa a los inventarios de las bibliotecas catedralicias y los libros poseídos por los eclesiásticos, es posible aproximarse al tipo de obras y autores que pudieron formar parte de los programas de estas escuelas. En relación con las obras referidas a las Artes Liberales y disciplinas afines estudiadas para los entornos catedralicios de las actuales diócesis castellanoleonesas, se ha comprobado que el aprendizaje de la lectura y escritura en los siglos XIV y XV no descansaba ya tanto en las gramáticas tardolatinas de Donato y Prisciano como en las gramáticas medievales. De estas últimas las más utilizadas fueron, sin duda, el Elementarium doctrine erudimentum o Vocabularium de Papias (siglo xI), el Catholicon de Ihoannes Balbus (siglo XII) y el Doctrinal de Alexandre de Villadei (siglo XIII). Más inusual es encontrar en los inventarios de estas bibliotecas catedralicias gramáticas de los humanistas, como las Regulae gramaticales de Guarino de Verona (1374-1460) y la gramática castellana de Antonio de Nebrija (1444-1522). Continuaron siendo muy usados instrumentos de consulta de léxico medievales como vocabularios y florilegios con extractos de citas de autores, así como las Etimologías de San Isidoro ${ }^{80}$. El dominio de las reglas gramaticales daba acceso a las otras dos disciplinas del Trivium (retórica y lógica). Las partes de la retórica correspondientes a la composición epistolar y redacción de documentos, cartas (ars ditaminis) ${ }^{81}$ y a la composición poética (ars poetriae) continuaron teniendo una posición preeminente

decurión como está dicho en el capítulo quarto de la arte que trata de la syntaxi y guardará en ella el estilo que los maestros pasados usaron que sea de más provecho para medianos y menores [...]. La primera lecçión de la tarde leerá el libro que le parezca de Suetonio, Valerio, alternando cada año y en la segunda y última leerá el libro quinto del arte que trata de prosodia y modo de componer versos con las figuras y repitirá este libro quarto y quinto dos o más veces cada año».

79 ACP, Armario IV, Leg. 2, n. ${ }^{\circ}$ 68, año 1570, fol. 4v: «Cap. 9. Cada sábado y si fuere fiesta el día antes en cada clase y aula por la mańana se relean todas las lecçiones de la semana leýdas por las mańanas y acabada esta lecçión nuestro cathedrático luego convocará toda la escuela a su aula mayor y les hará una plática de una hora del doctrina christiana declarándoles por el discurso del año los artículos de nuestra Santa Fee que contiene el Credo y los diez mandamientos del dechálogo y los cinco de la iglesia y cómo se an de confesar y procurará que todos sepan la doctrina christiana de memoria y ayudar a missa y cossas tocantes a buenas costumbres y cada sábado por la tarde en la primera lecçión en cada aula y classe se releerá todo lo de la semana leýdo y por la tarde».

80 Guijarro González, Susana. Maestros, escuelas y libros. El universo cultural de las catedrales en la Castilla Medieval. Madrid: Editorial Dykinson-Universidad Carlos III, 2004, pp. 297-298.

81 ACB, inventario 2, siglo xiv, n. ${ }^{\circ}$ 16: Mansilla Reoyo, Demetrio. Catálogo de los códices de la Catedral de Burgos. Madrid: Instituto Enrique Flórez, 1952, pp. 155-186; e inventario 6, siglo Xv, n. ${ }^{\circ}$ 19: «Summa magistri Guidonis», que es probablemente el Ars dictaminis de Guido de Faba, cfr. Camargo, Martín. Ars dictaminis, ars dictandis. Turnhout: Brepols, 1991, p. 40. ACP, inventario de 1481, ed. Ruiz Asencio, José Manuel. "Documentos sobre los manuscritos medievales de la catedral de Palencia». En Actas del II Congreso de Historia de Palencia. Palencia: Diputación Provincial, 1990, vol. 2, pp. 11-51, n. ${ }^{\circ} 178$ «de epistolis Petri de Veys (Pedro de Viena, †1249)». Vid. Guijarro González, Susana. "Cultura e intereses librísticos en la catedral de Palencia durante el siglo Xv». En La memoria de los libros: Estudios sobre la historia del escrito y de la lectura en Europa y América. Salamanca: Instituto de Historia del Libro y la Lectura, 2004, vol. 1, pp. 744-746. 
LAS ESCUELAS DE GRAMÁTICA EN LA CASTILLA BAJOMEDIEVAL (SIGLOS XIII-XV)

SUSANA GUIJARRO GONZÁLEZ

en el currículum que ya se advierte desde el siglo XIII. El ars dictaminis tomó algunos de los principios de la redacción de cartas y documentos del De inventione de Cicerón tan útiles para la formación de notarios y profesionales del Derecho. Pero es la biblioteca de algún prelado la que aporta alguna pista sobre el influjo de las escuelas italianas con la presencia de la Retórica de Aristóteles, traducida al latín en el siglo xiII, y la retórica de Petrarca (1304-1374 $)^{82}$. Sobresalen especialmente dos prelados burgaleses entre los introductores y seguidores del humanismo en el siglo xv castellano. En primer lugar, el obispo Alfonso de Cartagena (1384-1456) quien tradujo el De inventione de Cicerón entre 1420 y 1424, defendiendo que en la retórica importa tanto el contenido como la forma. Entendía que la belleza de la elocuencia no estaba solo en la imitación literal de la dicción y sintaxis clásicas sino en la claridad y autenticidad de las ideas expresadas ${ }^{83}$. En la biblioteca del obispo Luis de Acuña (1456-1495) no faltaban ni la retórica de Cicerón, ni la de Petrarca, ni la de Aristóteles, como se verá seguidamente.

La poesía había formado parte del canon escolar altomedieval por su valor nemotécnico y su capacidad para transmitir la verdad. Aimeric incluyó en su Ars Lectori (1086) a un poeta entre los dos autores clásicos, Salustio y Ovidio, que citó. No se hallan en los inventarios librísticos castellanoleoneses tantos autores clásicos como cabía esperar para los siglos XIV y XV, aunque en los de Salamanca, Burgos y Palencia se encuentran Virgilio, cuyas obras sirvieron de manuales de poesía, Ovidio, Cicerón, Séneca y los Dísticos de Catón, una colección de dichos orales compilada en la Antigüedad tardía que disfrutó de gran predicamento en los programas escolares bajomedievales. Junto a ellos aparecen los historiadores Flavio-Josefo y Plinio ${ }^{84}$. Los autores clásicos eran una fuente de contenido moral que ahondaba en la asociación entre la gramática y la ética que debía moldear la personalidad del estudiante en las virtudes y que explica la presencia en las bibliotecas de la Ética de Aristóteles y de las llamadas Sumas de vicios y virtudes, especialmente la escrita por Guillermo de Peraud ${ }^{85}$. En concreto, los

82 ACB, Testamento del obispo Acuña: López Martínez, Nicolás. «La biblioteca de Don Luis de Acuña en 1496». Burgense, 1961, vol. 2, pp. 80-109, n. ${ }^{\circ} 144$ y n. ${ }^{\circ} 31$ : posiblemente Cicerón (De inventione), n. ${ }^{\circ}$ 215: «Retórica de Aristóteles», n. ${ }^{\circ} 228$ y n. ${ }^{\circ} 241$ : «Retórica de Aristóteles»; n. ${ }^{\circ} 237$ : «Retórica Petrarche». Mención inconcreta a una retórica (ACB, Libro de Registros 8, fol. 93v).

83 Delgado Jara y Herrera García, «Humanidades y humanistas en la Universidad de Salamanca», p. 256.

84 ACSE (Archivo de la Catedral de Segovia), doc. F-15, año 1499, testamento del maestrescuela Juan García: «Eneida» de Virgilio. ACS (Archivo de la Catedral de Salamanca), Caj. 20, leg. 1, n. ${ }^{\circ}$ 29- $1 .^{\circ}$ y 2..$^{\text {: }}$ "Ovidio». ACB, Testamento del obispo Acuña: López Martínez, «La biblioteca de Don Luis de Acuña en 1496», n. ${ }^{\circ}$ 100: "Josefe, de antiquitate». ACB, inventario 1, siglo xiv: Mansilla Reoyo, Catálogo de los códices de la Catedral de Burgos, n. ${ }^{\circ}$ 70: "Item otro libro que llaman Plinio». ACB, inventario 6, siglo xv: Mansilla Reoyo, Catálogo de los códices de la Catedral de Burgos, n. ${ }^{\circ} 11$ : «Libro que se llama Plinio». ACB, Testamento del obispo Acuńa: López Martínez, «La biblioteca de Don Luis de Acuña en 1496», n. ${ }^{\circ} 22:$ «el Plineo, de natural ystoria»; n. ${ }^{\circ} 204:$ «Tulio, de ofççiis»; n. ${ }^{\circ} 31$ : «Marco tulio»; n. ${ }^{\circ} 259$ : "Oraciones de Tulio»; n. ${ }^{\circ}$ 213: «las posiciones de Séneca». Se encuentran también menciones inespecíficas a textos poéticos. ACB, Testamento del obispo Acuña: López Martínez, «La biblioteca de Don Luis de Acuña en 1496», n. ${ }^{\circ} 231$ : "Libro de poesía»; ACP, inventario de 1481, Ruiz AsEncio, «Documentos sobre los manuscritos medievales de la catedral de Palencia», n. ${ }^{\circ}$ 3: «la glosa de Catón».

85 ACB, Libro de Registros 8, fol. 93v, año 1445: «Éticas de filosofía»; año 1490: "Etica». ACB, Testamento del obispo Acuña: López Martínez, «La biblioteca de Don Luis de Acuña en 1496», n. ${ }^{\text {os }} 279$ y 285 : 
humanistas italianos del siglo XIV abordaron un nuevo Cicerón tras el redescubrimiento de buena parte de sus cartas y oraciones, enfatizando su utilidad escolar como modelo para componer en prosa, para forjar un estilo, así como para la oratoria. Algunos de los eminentes profesores de filosofía moral en la Facultad de Artes de Salamanca nos ponen sobre la pista del Aristóteles interpretado por los humanistas en relación con la Ética. Pedro de Osma (ca 1430-1480) tomó como base de sus lecciones la traducción de la Ética de Aristóteles realizada por Leonardo Bruni (1370-1444). El Aristóteles de los humanistas que no solo buscan al filósofo sino también al estilista (la Retórica y la Poética) se contrapuso al Aristóteles de los escolásticos, instrumentalizado en función de fines religiosos ${ }^{86}$.

Otros dos géneros escritos que sirvieron a la asociación entre la enseñanza gramatical y la adquisición de las virtudes cristianas que el humanismo transformó en cívicas fueron la historia y los tratados políticos. La historia había sido desde la Alta Edad Media la fuente por excelencia de enseńanzas morales y no era concebida como una disciplina escolar en sí misma. Pero en el currículum de los Studia humanitatis alcanzó un puesto de honor junto con la retórica y la poesía, favoreciendo el estrecho lazo que este programa estableció con la vida cívica. Los humanistas la percibieron como un depósito inagotable de ejemplos y de elocuencia e hicieron de su estudio desde comienzos del siglo XV una parte indispensable de los hombres con responsabilidad pública. Este extremo puede apreciarse con claridad en las bibliotecas de la nobleza laica y de los dignatarios eclesiásticos ${ }^{87}$. De las bibliotecas catedralicias castellanas se deduce la pervivencia del interés por historiadores romanos como Valerio Máximo (siglo I a. C.), Justino (siglos II-III d. C.), Suetonio (ca †126); tardoantiguos como Solinus (siglo III), Eusebio de Cesarea $(† 339)$ y Eutropio (siglo IV); así como por crónicas de la temprana Edad Media como las del Pesudo-Turpinus (†ca 800) o la Crónica Pseudo-isidoriana ${ }^{88}$. Más propio de ambientes

"casis eticorum»; n. ' 239: «Éticas». ACB, inventario 1: Mansilla Reoyo, Catálogo de los códices de la Catedral de Burgos, n. ${ }^{\circ}$ 39: "vitiis et virtutibus». ACB, inventario de 1481: Mansilla Reoyo, Catálogo de los códices de la Catedral de Burgos, n. 0 22a: «suma de vicios y virtudes». ACP, inventario de 1481: Ruiz Asencio, «Documentos sobre los manuscritos medievales de la catedral de Palencia», n. ${ }^{\circ} 22 \mathrm{~b}$ : «summa de vitiis et virtutibus»; n. ${ }^{\circ} 23$ : «Tractatus de virtutibus, comiença presens opus».

86 Labajos Alonso, José. «Pedro de Osma: impulsor del humanismo y del conocimiento de Aristóteles en Salamanca». Cuadernos Salmantinos de Filosofía, 1995, vol. 22, pp. 135-158.

87 Pueden verse en los estudios de Isabel Beceiro sobre las bibliotecas y cultura nobiliaria castellana, especialmente: Beceiro Pita, Isabel y Franco Silva, Alfonso. «Cultura nobiliar y bibliotecas. Cinco ejemplos, de las postrimerías del siglo XIv a mediados del siglo XvI». Historia. Instituciones. Documentos, 1985 , vol. 12, pp. 277-350; y Beceiro Pita, Isabel. «Bibliotecas y humanismo en el reino de Castilla: un estado de la cuestión». Hispania, 1990, vol. 50, n. ${ }^{\circ} 175$, pp. 827-839.

$88 \mathrm{ACB}$, inventario 1, siglo xiv: Mansilla Reoyo, Catálogo de los códices de la Catedral de Burgos, n. 77 e inventario 6, n. ${ }^{\circ}$ 41: "Soliloquium de mirabilibus mundo" de Solinus. ACB, inventario 1, siglo XIV: Mansilla Reoyo, Catálogo de los códices de la Catedral de Burgos, n. 41 e inventario 5, n. ${ }^{\circ}$ 12: "Historia eclesiástica» de Eusebio de Cesarea. ACB, Testamento del obispo Acuña: López MArtínez, "La biblioteca de Don Luis de Acuña en 1496», n. ${ }^{\circ}$ 344: «Historia eclesiástica». ACP, inventario de 1481: Ruiz AsEnCio, "Documentos sobre los manuscritos medievales de la catedral de Palencia», n. ${ }^{\circ}$ 10: "Genealogía de los Reyes de Francia, comiença Turpinus». ACB, inventario 1, siglo xiv: Mansilla Reoyo, Catálogo de los códices de la Catedral de Burgos, n. ${ }^{\text {os }} 50$ y 74: "un libro que se llama Corónica», título usual de la crónica pseudo-isidoriana. Los libros que poseía el vicario general de la diócesis de Sigüenza y fundador del Colegio de San Antonio 
culturales de los siglos XIV y XV es el interés por la historia de Roma, que deja algunos títulos que pudieran identificarse con la Historia Augusta (biografías de emperadores romanos) ${ }^{89}$, escrita hacia el siglo Iv. La historiografía producida en las cortes reales a partir del siglo XIII, especialmente la alfonsina, encuentra un hueco en algunas de las bibliotecas catedralicias estudiadas: la Crónica General de España, una Genealogía de los reyes de Francia e Castilla, el Libro de la destrucción de España y, posiblemente, la Historia Gothica del arzobispo Jiménez de Rada ${ }^{90}$.

No solo los nobles sino también algunos dignatarios eclesiásticos se interesaron por tratados políticos y tratados de educación de príncipes. Así en las bibliotecas catedralicias bajomedievales de Burgos y Palencia se encontraban el De regimine principum de Egidio de Fuscariis o Romano ( $\dagger 1316)$, el De essentia nobilitatis de Alexandro de Montemagno $(† 1466)$ y el Árbol de las batallas de Honoré de Bonet $(\dagger 1410)$, que tuvo una gran difusión entre regidores y gobernantes a pesar de versar sobre la guerra y sus leyes. Tanto el obispo Acuña como la biblioteca catedralicia burgalesa disponían de alguna traducción de la Política de Aristóteles, una obra que junto con sus comentarios planteaba cuestiones de fondo sobre el buen gobierno de la ciudad y sobre el poder en general ${ }^{91}$. En la Facultad de Artes de la Universidad de París se estudiaba la Política junto con la Ética de Aristóteles ${ }^{92}$. En el inventario del arzobispo de Toledo, García de Gudiel (1274), se registra una Ética a Nicómaco traducida de un ejemplar en romance, pudiera tratarse del comentario de Averroes a la Ética de Aristótoles. No hay que olvidar la deriva averroísta que se ha atribuido al aristotelismo hispano del siglo xIII representado en la Universidad de París por Mauricio el Hispano, como resultado de los intercambios culturales entre

de Portaceli, Juan López de Medina, incluyen un amplio y representativo elenco del humanismo incipiente en Castilla: Valerio Máximo, Suetonio, Justino y Eutropio entre los historiadores romanos, cfr. CHAcón Gómez-Monedero, «La biblioteca de don Juan López de Medina», pp. 338-339.

89 ACB, Vol. 24, fol. 131v, año 1492: "Capitolio de la Iglesia», quizás la obra de Julio Capitolino, n. ${ }^{\circ}$ 125. ACB, Testamento del obispo Acuña: López Martínez, «La biblioteca de Don Luis de Acuña en 1496», n. ${ }^{\text {os }} 15,23$ y 33: «Historia augusta» de Julio Capitolino. Se inventarían también otros títulos relativos a la historia de Roma tales como "Corónica romana» (ACB, Libro de Registros 3, fol. 167v, año 1446). ACB, inventario 4, siglo xiv: Mansilla Reoyo, Catálogo de los códices de la Catedral de Burgos, n. ${ }^{\circ}$ 33: "Corona romana»; «Libro de los Tratados de Roma» (ACB, Libro de Registros 8, fol. 130v, año 1498).

90 «Crónica de Espańa» (ACB, Libro de Registros 8, fol. 130v, ańo 1498). ACB, Testamento del obispo Acuña: López MarTínez, «La biblioteca de Don Luis de Acuña en 1496», n. ${ }^{\circ}$ 303: «Libro de la destrucción de España»; n. ${ }^{2}$ 296: "Crónica general de España»; n. o 35: «Crónica de España». ACSE, Doc. F-15, año 1468: «General Historia». ACP, inventario de 1481: Ruız AsENCIO, «Documentos sobre los manuscritos medievales de la catedral de Palencia», n. ${ }^{\circ}$ 197: «Crónica de los godos» (una de las denominaciones de la crónica del arzobispo Jiménez de Rada, pero también podría ser la pseudo-isidoriana).

91 ACB, inventario 2: Mansilla Reoyo, Catálogo de los códices de la Catedral de Burgos, n. ${ }^{\circ}$ 30: «Egidius de Fuscariis». ACB, Testamento del obispo Acuña: López Martínez, «La biblioteca de Don Luis de Acuńa en 1496», n. ${ }^{\circ}$ 280: «De regimini principum». ACP, inventario de 1481: Ruiz Asencio, «Documentos sobre los manuscritos medievales de la catedral de Palencia», n. ${ }^{\circ}$ 58: «De regimine principum». ACB, Testamento del obispo Acuńa: López Martínez, «La biblioteca de Don Luis de Acuña en 1496», n. 219: «De essentia nobilitatis»; n. ${ }^{\circ}$ 28: «Política de Leonardo». ACB, Libro de Registros 8, fol. 93v, ańo 1490: «Política» (posiblemente de Aristóteles). ACS, Caj. 23, leg. 1, n. ${ }^{\circ}$ 58, año 1480: «Árbol de las batallas».

92 Luscombe, David Edward. "Commentaries on the Politics: Paris and Oxford, XIII ${ }^{\text {th }}$-Xv" Centuries». En Weijers, Olga y Holtz, Louis (eds.). L'enseignement des disciplines à la Faculté des Arts (Paris et Oxford, XIIT-XV' siècles). Turnhout: Brepols, 1997, p. 314. 
cristianos, musulmanes y judíos en la Península. Por otra parte, se ha dicho que los libros morales de Aristóteles tuvieron poca cabida en los medios académicos hispanos antes del siglo Xv debido a la orientación de la filosofía moral hispana hacia una tradición oriental antigua de carácter didáctico-moral. Algo que ilustra bien el desarrollo de la literatura ejemplarizante y sapiencial de los siglos XIII y XIV. De todos modos, antes de la recepción completa de la Ética aristotélica al filo de 1200 ya se había introducido su concepto de los vicios y virtudes, así como su doctrina de la psicología moral. Otras obras del corpus aristotélico como la Lógica y el propio Cicerón sirvieron de cauces para la trasmisión de la ideas de la ética de Aristóteles ${ }^{33}$.

Más difícil es asociar la filosofía natural o Física de Aristóteles con el programa de las escuelas o Estudios de gramática. Hasta ahora solo en el caso del Estudio de gramática de Daroca, reconstruido a instancias del rey de Aragón, Pedro IV de Aragón, se dispone la existencia de maestros en "arte, lógica y natura», expresión esta última que alude a la Física o filosofía natural de Aristóteles y sus comentadores ${ }^{94}$. Desde luego, en las bibliotecas catedralicias de las que se viene hablando las obras del corpus natural aristotélico están representadas. No en vano la filosofía natural proporcionaba un fundamento teórico a las concepciones existentes sobre el universo y la naturaleza que los eruditos medievales trataron de hacer compatible con la doctrina sagrada. Por otra parte, fue en el entorno de algunas catedrales donde tuvo lugar el movimiento de traducciones del saber greco-árabe al latín, especialmente las obras científicas, entre los siglos XI y XIII. Además de las propias obras que integraban la Física de Aristóteles (De caelo mundo y De proprietatibus animalibus) pueden hallarse testimonios en las bibliotecas catedralicias de comentarios medievales al corpus natural aristotélico desde Boecio (siglo vi) hasta Bartholomeus Anglicus $(\dagger 1250)^{95}$.

93 Nederman, Cary J. "Aristotelian ethics before the "Nicomachean Ethics": alternative sources of Aristotle's concept of virtue in the twelfth century». En Medieval Aristotelianism and its limits: Classical traditions in Moral and Political Philosophy, 12 th $-15^{\text {th }}$ Centuries. London: Variorum Reprints, 1997, pp. 55-75.

94 Falcón Pérez, Ledesma Rubio, Orcástegui Gros y Sarasa Sánchez, «Las universidades del reino de Aragón», p. 90.

95 ACB, Testamento del obispo Acuña: López Martínez, «La biblioteca de Don Luis de Acuña en 1496", n. ${ }^{\circ} 105$ y n. ${ }^{\circ} 285$ : «De caelo mundo» y «De las propiedades de los animales». ACP, inventario de 1481: Ruiz AsEncio, "Documentos sobre los manuscritos medievales de la catedral de Palencia», n. 240 : «De proprietatibus animalium». ACB, inventario 2, siglo xiv: Mansilla Reoyo, Catálogo de los códices de la Catedral de Burgos, n. ${ }^{\circ}$ 18: "Tablas de filosofía que comiença en la primera foja: abstrahere in libro fisicorum», este incipit responde a un comentario anónimo al De proprietatibus animalium de Aristóteles, cfr. PATTIN, Adriaan. Repertorium commentariorum Medii Aevi in Aristotelem latinorum quae in bibliothecis belgicis asservantur. Leuven-Leiden: University Press-E. J. Brill, 1978, p. 151. ACB, inventario 4, siglo xiv: MansiLlA Reoyo, Catálogo de los códices de la Catedral de Burgos, n. ${ }^{\circ}$ 6: "Libros naturales de philosofía» (posiblemente la Física de Aristóteles o comentarios a la misma). ACB, inventario 2, siglo xiv: Mansilla Reoyo, Catálogo de los códices de la Catedral de Burgos, n. ${ }^{\circ}$ 13: "Questiones super libro fisicorum de pergamino sin tablas e sin coberturas que comiença en la primera foja que et utrum de natalibus poste», posiblemente una obra médica o de filosofía natural). ACP, inventario de 1481: RuIz AsEncio, «Documentos sobre los manuscritos medievales de la catedral de Palencia», n. 231 : «De filosofía moral y medicina». Tras este inusual título pudiera estar el Pseudo-aristotélico Secreta secretorum, que, aunque ofrece consejos sobre el arte de gobernar y sus connotaciones morales, incluye también información sobre la naturaleza del cuerpo humano y el mundo natural. ACS, Caj. 20, leg. 2, n. ${ }^{\circ}$ 17, año 1382: «De proprietatibus rebus» (pudiera ser el comentario de 
LAS ESCUELAS DE GRAMÁTICA EN LA CASTILLA BAJOMEDIEVAL (SIGLOS XIII-XV)

SUSANA GUIJARRO GONZÁLEZ

\section{Conclusión}

Las escuelas y los programas escolares constituyen para cualquier época que se afronte un tema de investigación que se encuentra en la encrucijada de varias disciplinas académicas no siempre suficientemente conectadas. Para el historiador de las sociedades medievales es un campo de investigación de las interacciones entre la Iglesia y las sociedades e instituciones laicas. En la Corona de Castilla la ausencia para la Baja Edad Media de una fuente tan importante para conocer las relaciones y negocios privados como son los archivos de protocolos notariales hace que el fresco de las escuelas de gramática pueda observarse tan solo a grandes rasgos. La visión que nos devuelve coincide en sus líneas principales con lo que sucedía en otros reinos hispanos y europeos. Las escuelas de gramática (escuelas de Artes o "Estudios») dependientes del cabildo catedralicio, a veces llamadas mayores para distinguirlas de otras que podían existir, continúan siendo determinantes en la enseñanza ofrecida en las ciudades bajomedievales castellanas. A pesar del peso de la titularidad eclesiástica de estas escuelas, los signos de apertura a la sociedad laica son evidentes desde la segunda mitad del siglo XIV. El aumento del número y grado de los docentes (maestros, lectores, repetidores, etc.) en ciudades catedralicias y villas importantes corre paralelo al del número de estudiantes que tienen cabida en las casas alquiladas por el regente de las escuelas. Es muy posible que los alumnos que no eran al menos clérigos de órdenes menores tuviesen que pagar una cuota al maestro. Es también probable que hubiese contratos orales privados entre maestros y familias que no han dejado huella. En cambio, sí se documentan algunos testimonios de la fundación de Estudios/colegios por mecenas eclesiásticos y por el poder real que no excluyen la participación de los gobiernos municipales en el gobierno y pago de salarios a los maestros de los mismos. Detrás de este interés de los poderes laicos está la oligarquía de caballeros y mercaderes-artesanos de las ciudades castellanas que demandan educación para sus hijos. Esta oligarquía urbana es la mayor beneficiaria de los programas académicos ofrecidos por las escuelas de gramática que en algunos casos pudieron ofrecer un nivel de enseñanza equiparable al del grado de bachiller obtenido en las Facultades de Artes de las Universidades del reino. Sigue siendo controvertido hablar de ruptura en un modelo de enseñanza de la gramática que desde la Alta Edad Media estuvo asociado a la adquisición de las virtudes cristianas y, por tanto, de la ética. Ello no impide, sin embargo, atisbar en las materias impartidas y en las obras y autores utilizados la influencia de los Studia humanitatis en el siglo xv. Aunque el paisaje de las escuelas castellanas bajomedievales sea multipolar y carente de una legislación única, la enseñanza de la gramática en su más amplio sentido las dotó de uniformidad. El enfoque filológico, histórico y moral de la misma pertrechaba a sus beneficiarios de las virtudes cívicas que configuraron la cultura urbana en los siglos finales del Medievo.

Bartholemeus Anglicus a la obra aristotélica del mismo, dada la difusión bajomedieval de la que este disfrutó). ACB, Testamento del obispo Acuña: López Martínez, "La biblioteca de Don Luis de Acuña en 1496", n. ${ }^{\text {os }}$ 199 y 202: «Glosa de Boeçio» y «Boeçio». 
LAS ESCUELAS DE GRAMÁTICA EN LA CASTILLA BAJOMEDIEVAL (SIGLOS XIII-XV)

SUSANA GUIJARRO GONZÁLEZ

36

\section{ReFERENCIAS BIBLIOGRÁFICAS}

Bartolomé Martínez, Bernabé. «Instituciones docentes: Universidades y colegios universitarios». En Historia de la educación en España y América. La educación en la España antigua y medieval. Madrid: Fundación Santamaría-Ediciones SM, 1992, vol. 1, pp. 554-602.

Beceiro Pita, Isabel. «Bibliotecas y humanismo en el reino de Castilla: un estado de la cuestión». Hispania, 1990, vol. 50, n. ${ }^{\circ} 175$, pp. 827-839.

Beceiro Pita, Isabel y Franco Silva, Alfonso. "Cultura nobiliar y bibliotecas. Cinco ejemplos, de las postrimerías del siglo XIV a mediados del siglo XVI». Historia. Instituciones. Documentos, 1985, vol. 12, pp. 277-350.

Beltrán de Heredia, Vicente. Bulario de la Universidad de Salamanca (1219-1549). 3 vols. Salamanca: Universidad de Salamanca, 1966-1967.

Black, Robert. Humanism and Education in Medieval and Renaissance England. Tradition and Innovation in Latin Schools from the Twelfth to the Fifteenth Century. Cambridge: Cambridge University Press, 2001.

Blasco Martínez, Asunción. «El Estudio de Artes en Zaragoza (siglos XIV-Xv)». Memoria Ecclesiae, 1988, vol. 12, pp. 251-276.

CAEsAR, Mathieu. "Écoles urbaines, pouvoir municipal et éducation civique à la fin du Moyen Âge. Quelques observations à partir du cas genevois aux XIV $\mathrm{XVV}^{\mathrm{e}}$ siècles». Histoire Urbaine, 2011, vol. 32, pp. 53-72.

Calleja Guijarro, Tomás. «Clemente Sánchez de Vercial y el estudio de la gramática de Sepúlveda". Archivos Leoneses. Revista de Estudios y Documentación de los Reinos Hispano-Occidentales, 1988, vol. 83-84, pp. 339-362.

Camargo, Martín. Ars dictaminis, ars dictandis. Turnhout: Brepols, 1991.

Castellanos Oñate, José Manuel. «El Estudio de gramática». Madrid Histórico, 2009, vol. 19, pp. 48-52.

Chacón Gómez-Monedero, Francisco A. «La biblioteca de don Juan López de Medina, fundador del Colegio-Universidad de San Antonio de Portaceli de Sigüenza». Wad-al-Hayara: Revista de Estudios de Guadalajara, 2003, vol. 30, pp. 313-348.

Cruselles Gómez, José María. Escuela y sociedad en la Valencia bajomedieval. Valencia: Diputación de Valencia, 1997.

Delgado Criado, Buenaventura. «La educación en Aragón: política educativa e instituciones docentes». En Historia de la educación en España y América. La educación en la España antigua y medieval. Madrid: Fundación Santamaría-Ediciones SM, 1992, vol. 1, pp. 318-345.

Delgado Jara, Inmaculada y Herrera García, Rosa María. «Humanidades y humanistas en la Universidad de Salamanca en el siglo Xv». En Rodríguez-San Pedro Bezares, Luis Enrique y Polo Rodríguez, J. L. (eds.). Salamanca y su Universidad en el primer Renacimiento. Siglo XV. Salamanca: Universidad de Salamanca, 2011, pp. 241-265.

Falcón Pérez, María Isabel; Ledesma Rubio, M. a Luisa; Orcástegui Gros, Carmen y Sarasa SÁnchez, Esteban. «Las universidades del reino de Aragón (Huesca y Zaragoza) y de Lérida en la Edad Media». En Estudios sobre los orígenes de las universidades españolas. Homenaje de la Universidad de Valladolid a la de Bolonia en su IX centenario. Valladolid: Universidad de Valladolid, 1988, pp. 85-95.

García y García, Antonio (ed.). Synodicon Hispanum I. Galicia. Madrid: Biblioteca de Autores Cristianos, 1981.

Garin, Eugenio. La educación en Europa. 1400-1600. Barcelona: Crítica, 1987.

Gent, Paul F. A Moral Art. Grammar, Society and Culture in Trecento Florence. Ithaca-New York: Cornell University Press, 1993. 
LAS ESCUELAS DE GRAMÁTICA EN LA CASTILLA BAJOMEDIEVAL (SIGLOS XIII-XV)

SUSANA GUIJARRO GONZÁLEZ

González García, Miguel Ángel. «La cátedra de gramática de la Catedral de Ourense». Memoria Ecclesiae, 1998, vol. 12, pp. 71-82.

Grafton, Anthony y Jardine, Lisa. From Humanism to the Humanities. Education and the Liberal Arts in Fifteenth-and Sixteenth-Century Europe. Cambridge-Massachusetts: Harvard University Press, 1986.

Grendler, Paul F. Schooling in Renaissance Italia. Literacy and Learning. 1300-1600. BaltimoreLondon: The John Hopkins University Press, 1989.

Guijarro GonzÁlEz, Susana. «Antigüedad, costumbre y exenciones frente a innovación en una institución medieval: el conflicto entre el maestrescuela y el cabildo de la Catedral de Burgos (1456-1472)». Hispania Sacra, 2008, vol. 60, n. ${ }^{\circ} 121$, pp. 67-94.

Guijarro González, Susana. "Cultura e intereses librísticos en la catedral de Palencia durante el siglo XV». En La memoria de los libros: Estudios sobre la historia del escrito y de la lectura en Europa y América. Salamanca: Instituto de Historia del Libro y la Lectura, 2004, vol. 1, pp. 735-760.

Guijarro González, Susana. La transmisión social de la cultura en la Edad Media castellana (siglos $X I-X V$ : las escuelas y la formación del clero de las catedrales. Tesis doctoral. Santander: Universidad de Cantabria, ed. en microficha, 1992.

Guijarro González, Susana. Maestros, escuelas y libros. El universo cultural de las catedrales en la Castilla Medieval. Madrid: Editorial Dykinson-Universidad Carlos III, 2004.

Labajos Alonso, José. «Pedro de Osma: impulsor del humanismo y del conocimiento de Aristóteles en Salamanca». Cuadernos Salmantinos de Filosofía, 1995, vol. 22, pp. 135-158.

Las Siete Partidas del Rey Alfonso X, ed. de la Real Academia de la Historia. Madrid: Imprenta Real, 1807.

López Alsina, Fernando. «Marzoa, Melgar, Muros, Fonseca: de las escuelas de gramática medieval al Estudio universitario en Galicia». En En el camino hacia la gloria. Miscelánea en honor de Monseñor Eugenio Romero Pace. Compostellanum. Santiago, 1999.

López Martínez, Nicolás. «El Colegio de San Nicolás». Boletín de la Comisión Provincial de Monumentos de Burgos, 1930-1933, vol. 3, pp. 9-17.

López Martínez, Nicolás. «La biblioteca de Don Luis de Acuña en 1496». Burgense, 1961, vol. 2, pp. 80-109.

Luscombe, David Edward. "Commentaries on the Politics: Paris and Oxford, XIII ${ }^{\text {th }}-\mathrm{Xv}^{\text {th }}$ Centuries». En Weijers, Olga y Holtz, Louis (eds.). L'enseignement des disciplines à la Faculté des Arts (Paris et Oxford, XIII -XV siècles). Turnhout: Brepols, 1997, pp. 313-327.

Mansi, Jean D. (ed.). Sacrorum Conciliorum nova et amplissima collectio, reimpresión. Graz, 19601962.

Mansilla Reoyo, Demetrio. Catálogo de los códices de la Catedral de Burgos. Madrid: Instituto Enrique Flórez, 1952.

Martínez Ángel, Lorenzo, «Instituciones educativas medievales leonesas. La escuela catedralicia». Estudios Humanisticos. Geografía, Historia y Arte, 1996, vol. 18, pp. 147-160.

Minguella y Arnedo, Toribio. Historia de la diócesis de Sigüenza y de sus obispos. Vol. 2. Colección diplomática. Madrid: Imprenta de la Revista de Archivos, Bibliotecas y Museos, 1901-1913.

Nederman, Cary J. "Aristotelian ethics before the "Nicomachean Ethics": alternative sources of Aristotle's concept of virtue in the twelfth century». En Medieval Aristotelianism and its limits: Classical traditions in Moral and Political Philosophy, $12^{\text {th }}-15^{\text {th }}$ Centuries. London: Variorum Reprints, 1997, pp. 55-75.

Nieto Cumplido, José Manuel. Historia de Córdoba, II. Islam y Cristianismo. Córdoba: Monte de Piedad y Caja de Ahorros, 1984.

Orme, Nicholas. Education and Society in Medieval and Renaissance England. London-Ronceverte: Hambledon Press, 1989. 
Pattin, Adriaan. Repertorium commentariorum Medii Aevi in Aristotelem latinorum quae in bibliothecis belgicis asservantur. Leuven-Leiden: University Press-E. J. Brill, 1978.

Pueyo Colomina, Pilar. «Documentos sobre maestros en Artes en la diócesis de Zaragoza en la segunda mitad del siglo xIv». Memoria Ecclesiae, 1998, vol. 12, pp. 189-213.

Quintana Prieto, Augusto. «Constituciones capitulares de los cabildos espańoles del siglo XiII». Anthologica Annua, 1981, vol. 28-29, pp. 484-529.

Ruiz Asencio, José Manuel. «Documentos sobre los manuscritos medievales de la catedral de Palencia». En Actas del II Congreso de Historia de Palencia. Palencia: Diputación Provincial, 1990, vol. 2, pp. 11-51.

Russell, James E. German Higher Schools. The History, Organization and Methods of Secondary Education in Germany. London-Bombay-Calcuta: Longmans, 1910.

Sáez, Emilio. Colección diplomática de Sepúlveda. Segovia: Diputación Provincial de Segovia, 1961, 2 vols.

Sánchez Herrero, José. «El Estudio de San Miguel de Sevilla durante el siglo Xv». Historia. Instituciones. Documentos, 1983, vol. 10, pp. 297-324.

SÁNCHez Herrero, José. «La actividad educadora, directa e institucional: las escuelas de gramática monásticas y catedralicias». En Bartolomé Martínez, Bernabé (dir.). Historia de la acción educadora de la Iglesia en España. Madrid: Biblioteca de Autores Cristianos, 1995, vol. 1, pp. 290-314.

SAnZ GonZÁlez, Mariano. «La reforma de la Iglesia en los sínodos de Juan Arias Dávila». En GALINDo García, Ángel (ed.). Arias Dávila: obispo y mecenas. Segovia en el siglo XV. Salamanca: Universidad Pontificia de Salamanca, 1998, pp. 417-453.

Tejada y Ramiro, Juan (ed.). Colección de cánones y de todos los concilios de la Iglesia de España y América. Madrid: Imprenta Pardo Montero, 1859-1863. 